\title{
Melatonin-induced Cell Rejuvenation from Long- term Ex-vivo passaging Functioned by its Restoration of Damaged Cell Autophagic Processes
}

\section{Yi-Zhou Tan}

Fourth Military Medical University School of Stomatology: Air Force Medical University School of Stomatology

Xin-Yue Xu

Fourth Military Medical University School of Stomatology: Air Force Medical University School of Stomatology

Ji-Min Dai

Fourth Military Medical University: Air Force Medical University

\section{Yuan Yin}

Fourth Military Medical University School of Stomatology: Air Force Medical University School of Stomatology

\section{Xiao-Tao He}

Fourth Military Medical University School of Stomatology: Air Force Medical University School of Stomatology

\section{Yi-Lin Zhang}

Fourth Military Medical University School of Stomatology: Air Force Medical University School of Stomatology

\section{Tian-Xiao Zhu}

Fourth Military Medical University School of Stomatology: Air Force Medical University School of Stomatology

\section{Ying An}

Fourth Military Medical University School of Stomatology: Air Force Medical University School of Stomatology

\section{Bei-Min Tian}

Fourth Military Medical University School of Stomatology: Air Force Medical University School of Stomatology

Fa-Ming Chen ( $\square$ cfmsunhh@fmmu.edu.cn )

School of Stomatology, Fourth Military Medical University https://orcid.org/0000-0002-8398-2104

\section{Research}


Keywords: Melatonin, Cellular senescence, Cell aging, Autophagy, Cell expansion, Translational medicine Posted Date: December 11th, 2020

DOI: https://doi.org/10.21203/rs.3.rs-122498/v1

License: (c) (1) This work is licensed under a Creative Commons Attribution 4.0 International License. Read Full License 


\section{Abstract}

Background: Stem cells undergone long-term ex-vivo expansion are most likely functionally compromised (namely cellular senescence) in terms of their stem cell properties and therapeutic potentials. Due to the ability to attenuate cellular senescence, melatonin (MLT) has been proposed as an adjuvant across longterm cell expansion protocols, but the underlying mechanism remains largely unknown.

Methods: Human periodontal ligament stem cells (PDLSCs) were isolated and cultured ex-vivo for 15 passages, and passage 2, 7 and 15 cells were used to interrogate the cellular senescence and alteration in cell autophagy during long-term expansion. The cellular senescence features were evidenced by senescence-associated $\beta$-galacotosidase (SA- $\beta$-gal) activity and the expression of senescence-related proteins including p53, p21, p16 and $\gamma-\mathrm{H} 2 \mathrm{AX}$. Electronic microscope was used to observe the autophagic vesicles. Adenovirus mRFP-GFP-LC3 was transfected to indicate the alteration of autophagic flux during long-term expansion, and the autophagy-associated proteins Atg7, Beclin-1, LC3-II and p62 were evaluated by Western blot.

Results: It was found that long-term in-vitro passaging led to an accumulated SA- $\beta$-gal, elevated expressions of p53, p21, p16 and $\mathrm{y}-\mathrm{H} 2 \mathrm{AX}$, along with downregulated autophagy-associated proteins Atg7, Beclin-1 and LC3 as well as a mounting autophagy substrate p62. In accordance with expectation, supplemented with MLT not only ameliorated cells to a younger state but also restored the impaired autophagy level in senescent cells. Additionally, we demonstrated that autophagy inhibitor could block such MLT-induced cell rejuvenation. When the underlying signaling pathways involved was interrogated, we found that MLT receptor (MT) participated in mediating MLT-related autophagy restoration by regulating $\mathrm{PI} 3 \mathrm{~K} / \mathrm{AKT} / \mathrm{mTOR}$ signaling pathway.

Conclusions: The present study suggests that MLT may rejuvenate long-term expansion-caused cellular senescence by restoring autophagy, more likely via PI3K/AKT/mTOR signaling pathway in an MTdependent manner. This is the first report identifying the MT-dependent PI3K/AKT/mTOR signaling involved in MLT-induced autophagy alteration, pointing to a potential target for using autophagy-restoring agents such as MLT to develop optimized clinical-scale cell production protocols.

\section{1 | Introduction}

Postnatal mesenchymal stromal cells (MSCs) can be isolated from many adult human tissues including but not limited to bone marrow, adipose tissue, skin, articular cartilage, brain and multiple dental tissues like periodontium. Although those cells have been demonstrated to be powerful therapeutics for various injuries and disorders in preclinical settings, how to expand quantity- and quality-assured cellular materials to be used in the clinical setting remains to be explored [1-3]. One major impediment in many if not all current scalable protocols is that cellular senescence occurs during long-term culture and hence compromise the subsequent therapeutic effects of MSCs in the clinical setting [4-7]. Successful cellular therapy requires sufficient quantity of robust cells, while production of cellular materials of interest to a 
clinical-scale necessitates a prolonged in-vitro cell expansion. Therefore, it is essential to enhance our knowledge about the culture-caused cell aging process and indeed to identify new agents to attenuate cellular senescence during long-term cell expansion.

The presence of senescence-associated $\beta$-galacotosidase (SA- $\beta$-gal), reactive oxygen species (ROS) accumulation, DNA damage, dysfunction of mitochondria [8], metabolism alteration [9], epigenetic modifications [10], and/or telomerase/chromosome anomalies can be identified in aging cells and hence all are indicative of senescence [11]. More importantly, accumulating evidence indicating that perturbed autophagy is more frequently found in senescent stem cells, suggesting a new target to rescue cell aging $[12,13]$. In fact, autophagy has long been believed to be an evolutionarily conserved catabolic process that plays a cytoprotective role in maintaining cellular homeostasis. In this context, recent investigations demonstrated that the deficient autophagy levels could cause the accumulation of dysfunctional macromolecules and organelles as well as imbalanced proteostasis and amino acid pools, leading to impaired metabolic functions. Interestingly, the promotion of autophagy could attenuate senescencerelated dysfunction. Similar to stem cells extracted from physiologically aged animal models, knock-out of certain autophagy-related proteins in stem cells resulted in a declined cell regeneration capacity [12, 14]. Therefore, it is reasonable to presume that autophagy-restoring agents should be able to be used in long-term and clinical-scale cell expansion to retain cells in a younger state.

Melatonin (MLT), N-acetyl-5-methoxytryptamine, is an endogenous hormone that firstly recognized as an important modulator of circadian rhythms, regulating various physiological bioactivities [15-17]. Due to its remarkable function of anti-oxidation, anti-apoptosis, immunological regulation and multi-lineage differentiation improvement [18-21], MLT has been used in many biological fields. Although the underlying mechanism remains unknown, in-vitro use of MLT demonstrated to prevent senescence of MSCs [22, 23], and its exogenous administration has been proved to be effective in prolonging longevity in several model organisms [24-26]. These findings indicate a close connection between MLT and cellular senescence. Although to some extent, treatment of stem cells using growth factors, cultivating cells in biomaterials mimicking in-vivo cell environment and gene-modification alone or in combination have applied in retarding cell senescent and maintaining stemness in many cell production protocols, these methods cannot be widely used due to high cost, technique complex and/or risk issues. Compared to expensive growth factors, complex biomaterials or intricate gene-modification strategies, commercially manufactured MLT is a natural agent that has been safely used in preclinical and clinical settings for either research or therapeutic purpose for decades. In this regard, it should be superior to other adjuvant in terms of safe, cost-effective and efficacy for large-scale of cellular materials undergone long-term expansion, despite the comprehensive mechanisms are still under investigation. When it comes to the therapeutic function of MLT, it is found that in-vivo MLT application could restore autophagic flux to impede cognitive decline and cardiac anomalies in Alzheimer disease (AD) animal models [27-28]. More recently, MLT demonstrated to down-regulate the PI3K/AKT in stem cells through MLT receptor (MT) [29]. Given that PI3K/AKT/mTOR pathway is a main signaling of autophagy regulation [30, 31], we hypothesize that the mechanism underlying MLT-induced retarding cells from senescence is attributed to 
its regulation of cell autophagy, and the MT/PI3K/AKT/mTOR signaling is likely to be an important pathway involved into this regulatory process.

To test our hypothesis, we isolated human periodontal ligament (PDL) stem cells (PDLSCs) in the present study using previous established protocol [32,33]. The obtained PDLSCs were cultured in-vitro for 15 passages, and passage 2 (P2), passage 7 (P7) and passage 15 (P15) cells were used to investigate cellular senescence and autophagy level caused by long-term expansion. Next, cellular responses of P2, P7 and P15 cells with MLT supplement were evaluated to test the biological function of MLT in maintaining cell stemness and indeed its ability to restore autophagy. Finally, we screened and verified the potential signaling pathways involved in the MLT-induced cell rejuvenation.

\section{2 | Materials And Methods}

\section{1 | Isolation and cultivation of PDLSCs}

Human PDLSCs were isolated from extracted third molars or orthodontic teeth from 6 donors (2 males, 4 females, aged $26.5 \pm 6.3$ ) admitted to Department of Oral and Maxillofacial Surgery, School of Stomatology, Fourth Military Medical University. All donors signed the informed consent form in advance. Extracted teeth were examined in advance to exclude periodontitis, and were immediately transferred into a centrifuge tube contained with complete cultural medium (a-minimum essential medium (a-MEM, Invitrogen) containing $100 \mathrm{U} / \mathrm{mL}$ penicillin (Invitrogen), $100 \mu \mathrm{g} / \mathrm{mL}$ streptomycin (Invitrogen), and 10\% fetal bovine serum (FBS; Sijiqing, Hangzhou, China) to laboratory. After repeatedly rinsing with sterile phosphate-buffered saline (PBS; Corning, New York, USA), PDL tissue was gently scraped from the middle of the root surface. The scraped tissue was collected and digested in $3 \mathrm{mg} / \mathrm{mL}$ type I collagenase (Sigma-Aldrich, St. Louis, USA) in $37^{\circ} \mathrm{C}$ for $1 \mathrm{~h}$. After digestion, tissues were seeded in 6-well plates (Invitrogen, Carlsbad, CA, USA) with complete cultural medium. The medium was changed every 2 days until cells migrated from the tissue and reached $80 \%$ confluence. We here recognized those primary cells as passage 0 cells (P0). Then the P0 cells were cultured in-vitro for 15 passages, while P2, P7 and P15 cells were labeled and cryopreserved at liquid nitrogen using CELLSAVING (New Cell \& Molecular Biotech, Suzhou, China). Cryopreserved P2, P7 and P15 cells from the same donor were recovered at the same time, grouped for the identification of MSC properties and further investigation.

\section{2 | Identification of PDLSCs \\ 2.2.1 | Flow cytometry analysis}

P2, P7 and P15 cells were digested, collected, and washed twice with PBS. Then cells were transferred into sterile Eppendorf tubes (Eppendorf, Hamburg, Germany) with at least $1 \times 10^{5}$ cells/tube. After respectively incubated at $4{ }^{\circ} \mathrm{C}$ in the dark for $1 \mathrm{~h}$ with monoclonal antibodies against human $\mathrm{CD} 90$, CD105, CD146, CD34, CD45, or CD31 (all from eBioscience, San Diego, CA, USA) at a 1:1000 dilution, while cells incubated with PBS were used as the negative control. The immunophenotypes of the cells were tested with a Beckman Coulter Epics XL cytometer (Beckman Coulter, Fullerton, CA, USA). 


\subsubsection{Colony formation assay}

P2, P7 and P15 cells were seeded into 100-mm culture dishes (Invitrogen) at the density of $1 \times 10^{3}$ cells/well. The medium was refreshed every 2 days for 10 days. Cells were then rinsed twice and were fixed using $4 \%$ paraformaldehyde (Servicebio, Wuhan, China) for 20 min and stained with $0.1 \%$ toluidine blue (Sigma-Aldrich, St. Louis, MO, USA) for $15 \mathrm{~min}$. Stained cells were rinsed to wash extra dye and were observed under stereomicroscope (Olympus Optical, Tokyo, Japan). Cells aggregate containing more than 50 cells were recognized as a colony.

\subsection{3 | Cell Counting Kit-8 (CCK-8) assay}

P2, P7 and P15 cells were seeded into 96-well plates (Invitrogen) at the density of $1 \times 10^{3}$ cells/well. The medium was refreshed every 2 days for 8 days. During the 8-day culture, $200 \mu \mathrm{L}$ medium with $20 \mu \mathrm{L} \mathrm{CCK}$ 8 reagent (Dojindo Corporation, Tokyo, Japan) was added to each well at an identical time every day, and the plate was incubated $37^{\circ} \mathrm{C}$ for $1 \mathrm{~h}$ before absorbance at $450 \mathrm{~nm}$ was detected with a microplate reader (TECAN, Männedorf, Switzerland) to measure the proliferation ability of cells.

\subsection{4 | Cell differentiation assay}

P2, P7 and P15 cells were seeded into 6-well dishes at the density of $5 \times 10^{5}$ cells/well. After cells reached $80 \%$ confluence, medium was changed into osteo-inductive medium, adipo-inductive medium or chondrogenic inductive medium (all from Cyagen, Guangzhou, China) to ascertain their multilineage differentiation capacity. Medium was refreshed every 2 days until 21 days for osteo-induction or adipoinduction, or 28 days for chondrogenic induction. After induction, mineralized nodes indicating osteogenesis, lipid droplets indicating adipogenesis or acidic poly-saccharides indicating chondrogenesis were visualized by Alizarin red staining (Sigma-Aldrich), Oil red O staining (Cyagen), and Alcian blue staining (Cyagen) respectively. To quantitatively analyse the mineralized nodules after Alizarin red staining, the mineralized nodules were dissolved with $6 \%$ cetyl-pyridine for $15 \mathrm{~min}$. Then the absorbance at $570 \mathrm{~nm}$ was tested by a microplate reader (TECAN).

\section{3 | Alkaline phosphatase (ALP) staining}

ALP activity in PDLSCs was analyzed by ALP staining. In brief, P2, P7 and P15 cells were seeded into 6well dishes at the density of $5 \times 10^{5}$ cells/well in complete medium. After cells reached $80 \%$ confluence, medium was changed into osteo-inductive medium for 7 days. ALP staining was performed afterwards using a BCIP/NBT ALP staining kit (Beyotime Institute of Biotechnology, Nantong, China) according to the manufacturer's instructions. ALP quantitative analysis was performed using an alkaline phosphatase assay kit (Nanjing Jiancheng Bioengineering Institute, Nanjing China) according to the manufacturer's instructions.

\section{4 | MLT concentration selection and supplement}

MLT (Sigma-Aldrich) was screened for the best concentration before supplemented into culture. MLT was added into basal medium at the concentration of $0,10 \mathrm{nM}, 100 \mathrm{nM}, 1 \mu \mathrm{M}, 10 \mu \mathrm{M}$ respectively $24 \mathrm{~h}$ before 
testing. To examine the viability of P15 cells with MLT supplement at different concentrations, CCK-8 assay was performed. Cells were seeded into 96 -well plate (Invitrogen) at the density of $5.0 \times 10^{3}$ cells/well. After MLT supplement for $24 \mathrm{~h}$, the CCK-8 reagent (Dojindo Corporation) was added to each culture well and incubated at $37^{\circ} \mathrm{C}$ for $1 \mathrm{~h}$. Absorbance at $450 \mathrm{~nm}$ was then detected with a microplate reader (TECAN). To detect the influence of different MLT concentration to cellular senescence and autophagy, the expression of senescence-related proteins including p53, p21, p16 and $y-H 2 A X$, and the expression of autophagy-related proteins including Atg7, p62, Beclin-1 and LC3-II were evaluated by qRTPCR and Western blot (see the sections of qRT-PCR and Western blot analysis). After finding out the optimum concentration, MLT was added into basal medium $24 \mathrm{~h}$ before tests.

\section{5 | Chemicals and reagents}

To inhibit the MLT-mediated autophagy elevation, 5 mM 3-methyladenine (3-MA, MedChemExpress, New Jersey, USA) was used as autophagy inhibitor, added into basal medium $24 \mathrm{~h}$ before tests. To inhibit the signaling mediated by MLT receptors, $1 \mu \mathrm{M}$ Luzindole (LUZ, MedChemExpress), a non-selective antagonist of MLT receptors, was added in the basal medium $24 \mathrm{~h}$ before tests. To investigate the possible pathway of MT-dependent autophagy, $1 \mu \mathrm{M}$ Luzindole, SC79 (PI3K/AKT activator), MHY1485 (mTOR activator) (all purchased in MedChemExpress) were added respectively into basal medium $24 \mathrm{~h}$ before tests as designed. To detect cellular autophagic flux, $1 \mu \mathrm{M}$ bafilomycin A1 (Baf, MedChemExpress), an inhibitor of autophagosome-lysosome fusion, was added for $4 \mathrm{~h}$ before tests. Each reagent was firstly dissolved in DMSO (Sigma-Aldrich) to form storing solution at the concentration of $10 \mathrm{mM}$ then diluted into final applied concentration by basal medium before use.

\section{6 | SA- $\beta$-gal activity analysis}

SA- $\beta$-gal activity is widely recognized during the detection of cellular senescence. SA- $\beta$-gal activity was detected using the senescence $\beta$-galactosidase staining kit (Cell Signaling T echnology (CST), MA, USA) as manufacturer's instruction. SA- $\beta$-gal positive cells were dyed in blue, observed and calculated based on three randomly selected bright fields. The percentage of SA- $\beta$-gal positive cells out of the total number of cells was analyzed.

\section{7 | Transmission electron microscopy}

To detect the autophagic vesicles, cells were fixed using $3 \%(\mathrm{w} / \mathrm{v})$ glutaraldehyde for at least $48 \mathrm{~h}$ at $4{ }^{\circ} \mathrm{C}$ and post-fixed with osmium tetroxide. Samples were dehydrated in a graded series of alcohol concentrations, embedded in epoxy resins, and sectioned. The autophagic vesicles in cells were observed with transmission electron microscopy (Hitachi, Tokyo, Japan)

\section{8 | Indirect immune fluorescent labeling and flow cytometry analysis}

The amount of LC3-II was evaluated by indirect immune fluorescent labeling for GFP-LC3 followed by flow cytometry analysis. Cells were fixed and permeabilized with commercial Fixation/Permeabilization Solution Kit (BD Biosciences Pharmingen, San Diego, USA) for 20 min at $4{ }^{\circ} \mathrm{C}$. After rinsed twice, cells 
were incubated with the LC3B-specific antibody (rabbit polyclonal, ProteinTech, Illinois, USA, \# 18725-1AP) at a 1:200 dilution in $4{ }^{\circ} \mathrm{C}$ overnight. Then cells were rinsed three times to remove extra primary antibody before incubated at room temperature in the dark for $2 \mathrm{~h}$ with the Dylight 488, goat anti-rabbit IgG (1:200, AntiProtech Inc, California, USA). The labeled cells were analyzed using a Beckman Coulter Epics XL cytometer (Beckman Coulter).

\section{9 | Detection of autophagic flux with adenovirus mRFP- GFP-LC3}

To detect autophagic flux, adenovirus mRFP-GFP-LC3 (HanBio Technology, Shanghai, China) were transfected into PDLSCs. Cells were seeded into confocal 24-well dishes (Xinyou Biotechnology, Hangzhou, China) at a density of $1 \times 10^{5}$ cells/well. After cells adhered and reached $50 \%$ confluence, adenovirus mRFP-GFP-LC3 was transfected according to the manufacturer's instructions. Medium was renewed $2 \mathrm{~h}$ after transfection to remove extra adenovirus. Pharmaceutical treatments were conducted $12 \mathrm{~h}$ after transfection. After respective treatment, transfected cells were fixed by $4 \%$ paraformaldehyde (Servicebio) and observed under the Olympus FV1000 laser confocal microscope (Tokyo, Japan). Both red and yellow puncta were counted and analyzed in the merged image based on three randomly selected fields.

\subsection{RNA extraction and qRT-PCR}

Total RNA was extracted using E.Z.N.A. Total RNA Kit II (OMEGA Bio-tek, Inc, GA, USA) according to the manufacturer's instructions. Extracted total RNA was reverse transcribed to CDNA using the PrimeScript RT reagent kit (TaKaRa, Shiga, Japan) as instructed. qRT-PCR analysis was performed using the SYBR Premix Ex Taq II kit (TaKaRa) and tested by a CFX96TM Real-time RT-PCR System (Bio-Rad, Hercules, CA, USA). $\beta$-actin was used to normalize the expression levels of the endogenous control. The resulting amplification and melt curves were analyzed to ensure the identity of the specific PCR product. Threshold cycle values were used to calculate the fold change in the transcript levels by using the $2^{-\triangle \triangle C t}$ method. The primers used for qRT-PCR were: $\beta$-actin: sense 5'-TGGCACCCAGCACAATGAA-3', and antisense $5^{\prime}$ CTAAGTCATAGTCCGCCTAGAAGCA-3'; p53: sense 5'-CAGCACATGACGGAGGTTGT-3' and antisense 5'TCATCCAAATACTCCACACGC-3'; p21: sense 5'-TGTCCGTCAGAACCCATGC-3' and antisen se 5'AAAGTCGAAGTTCCATCGCTC-3'; p16: sense 5'-GAAGAAAGAGGAGGGGCTG-3' and antisense 5'GCGCTACCTGATTCCAATTC-3'.

\subsection{1 | Western blot analysis}

Prepared cells were lysed in RIPA buffer (Beyotime) added with phosphatase inhibitors (Sigma-Aldrich). Protein concentration was measured using the bicinchoninic acid (BCA) method kit (Solarbio, Beijing, China). Protein samples were separated by sulfate-polyacrylamide gel electrophoresis (SDS-PAGE) (Beyotime). The concentration of applied SDS-PAGE gel was determined by molecule weight of proteins. That was, $15 \%$ for LC3, p16, y-H2AX and p21; 10\% for p-PI3K, PI3K, p-AKT, AKT, Atg7, Beclin-1, p53 and 
GADPH; and $6 \%$ for $\mathrm{p}-\mathrm{mTOR}$ and mTOR. The proteins were transferred onto PVDF membranes (Millipore, Billerica, MA, USA). After blocking with $5 \%$ non-fat milk at room temperature for $1 \mathrm{~h}$, the membrane was incubated with primary antibodies at $4{ }^{\circ} \mathrm{C}$ overnight and with the corresponding horse radish peroxidase (HRP)-conjugated secondary antibody (1:2000; goat anti-rabbit IgG, CST, \#7074; goat anti-mouse lgG, CST, \#7076) for $2 \mathrm{~h}$ at room temperature the next day. Finally, the blots were detected using enhanced chemiluminescence substrate (ECL kit, Millipore). The phosphorylated protein was normalized to the corresponding total protein. GAPDH was used as the housekeeping gene for internal normalization. ImageJ software was used to analyze protein bands. The primary antibodies used for Western blot were against p16 (1:1000; ProteinTech, \#10883-1-AP), p21 (1:1000; ProteinTech, \#10355-1-AP), p53 (1:1000; Abcam, Cambridge, Britain, ab26), Y-H2AX (1:1000; Abcam, ab229914), LC3 (1:1000; ProteinTech, \#14600-1-AP), p62 (1:1000; ProteinTech, \#18420-1-AP), Atg7 (1:1000; ProteinTech, \#10088-2-AP), Beclin1 (1:1000; ProteinTech, \#11306-1-AP), PI3K (1:1000; CST, \#4257), p-PI3K (Tyr458) (1:1000; CST, \#4228), AKT (1:1000; CST, \#4691), p-AKT (Ser473) (1:1000; CST, \#4060), mTOR (1:1000; CST, \#2983), and pmTOR (Ser2448) (1:1000; CST, \#5536).

\subsection{2 | Statistical Analysis}

The PDLSCs before and after long-term passaging for studies were from the identical donors. All assays were performed at least three times independently. GraphPad Prism 7 software was employed for statistical analysis. Differences between groups were assessed by one-way analysis of variance (Oneway ANOVA) followed by Tukey's multiple comparisons tests, Sidak's multiple comparisons tests, or Dunnett's multiple comparisons. The results were presented as the mean and standard deviation (mean \pm $\mathrm{SD}$ ). All the experiments were repeated in PDLSCs from at least 3 different donors. Statistical significance was expressed as $p<0.05(*), p<0.01(\star *), p<0.001(\star \star \star)$, or $p<0.0001(* \star \star *)$.

\section{3 | Results}

\section{1 | Long-term passaging causes cellular senescence}

PDLSCs were successfully isolated from PDL tissues from 6 donors (2 males, 4 females, aged $26.5 \pm 6.3$ ), and were expanded in-vitro for 15 passages. P2, P7 and P15 cells from the same donor were grouped for investigation. To determine whether the isolated and passaged cells can be used as PDLSCs, we detected cell surface markers of MSCs by flow cytometry analysis using previous established protocol. We found that all the P2, P7 and P15 cells positively expressed MSC markers including CD90, CD105, and CD146, while the endothelial cell marker (CD31) and hematopoiesis-related markers (CD34 and CD45) were negative (Fig. S1a). Besides, to confirm the differentiation potential towards cartilage, adipose and osseous tissue, we conducted the Alcian blue, Oil red O, Alizarin red and ALP staining. The stained acidic poly-saccharides, lipid droplets and mineralized nodes respectively suggested that the P2, P7 and P15 cells all had multi-linage differentiation potential including chondrogenesis, adipogenesis, and osteogenesis (Fig. S1b-d, f), while quantitative analysis of Alizarin red staining and ALP activity 
suggested the osteogenesis potential of PDLSCs in P15 significantly decreased after long-term passaging (Fig. S1e, g). Furthermore, as evaluated by colony-forming assay and CCK-8 assay, the cells from all passages were proved to possess the ability of colony-forming and proliferation. However, the ability of colony-forming and proliferation significantly declined along with long-term passaging (Fig. 1a, b). In parallel, the SA- $\beta$-gal activity, which reflects cellular senescence extent [34], was found markedly higher in P15 cells (Fig. 1C). To further verify cellular senescence after in-vitro expansion, we chose several senescence-associated genes including p16, p21, p53 and $\mathrm{Y}-\mathrm{H} 2 \mathrm{AX}$ for investigation. p16, p21 and p53 are recognized as cell cycle regulatory protein, whose increased expression often indicates disordered cell cycle. And $\mathrm{y}-\mathrm{H} 2 \mathrm{AX}$, manifesting discrete nuclear foci, could sensitively indicate DNA double-strand break damage. As evaluated by Western blot, the expression of these senescence-related proteins was found to increase after long-term passaging (Fig. 1d). Taken together, the senescenceassociated features including inhibited proliferation capacity, hindered osteogenesis potential, increased SA- $\beta$-gal activity, arrested cell cycle and DNA damage were observed in P7 cells and more prominently in P15 cells compared to P2 cells, suggesting long-term passaging caused cellular senescence.

\section{2 | Autophagy is impaired after long-term passaging}

Autophagy is a consecutive process including autophagosomes formation, maturation, fusion with lysosomes to form autolysosome, and degradation. The process from the formation to the degradation of autophagosomes is termed as autophagic flux. We first observed the autophagic vesicles in P2, P7 and P15 cells with electron microscopy. Accompanied by swollen mitochondria shown in P15 cells, the autophagic vesicles were scarcely observed (Fig. 2a). In order to detect the proceeding autophagic flux, adenovirus mRFP-GFP-LC3 (a tandem fluorescent-tagged microtubule-associated protein light chain 3 (LC3) reporter containing monomeric red fluorescent protein (mRFP) and GFP) was transfected into P2, P7 and P15 cells. Given that the fluorescence of GFP could be quenched due to low pH in lysosome, the red puncta indicate mature autolysosomes, while yellow puncta formed by the overlay of red and green puncta indicate non-fused autophagosomes. After long-term passaging, the number of red puncta (autolysosomes) prominently declined, suggesting a possible blockage of the formation of autophagosomes (Fig. 2b). To further verify whether the decline of autolysosomes in senescent cells was caused by inhibited formation or increased degradation, Baf, an inhibitor for lysosome formation was added $4 \mathrm{~h}$ before tests. After Baf supplement, yellow puncta (non-fused autophagosomes) were saturated in P2 cells because of the failure of autolysosome formation, while the accumulation of yellow puncta were blunted in P7 and P15 cells, suggesting the saturation of yellow puncta after Baf treatment was not resulted from increasing degradation but the blockage of autophagic flux (Fig. 2b). The formation of autophagosomes could also be indicated by the LC3-II, given that its localization on both outer and inner membranes of autophagosomes could accumulate after prohibiting autophagosomes degradation by Baf treatment. The amount of LC3-II showed no significant differences before and after Baf treatment in P7 and P15 cells as evaluated by flow cytometry analysis and Western blot, while LC3-II significantly accumulated in P2 cells after Baf treatment (Fig. 2c and 2d). These results all indicated the inhibited formation of autophagosomes in the cells after long-term expansion. As evaluated by Western blot, the 
expression of autophagy-related proteins including Atg7 and Beclin-1 decreased after long-term expansion, while the expression of autophagy substrates indicator p62 increased along with PDLSC senescence (Fig. 2e), indicating the impaired autophagy in senescent cells caused by long-term expansion.

\section{3 | MLT ameliorates PDLSC senescence and restores autophagy}

To investigate the effect of MLT to autophagy in senescent PDLSCs, MLT was supplemented to basal medium. Firstly, MLT concentration was screened for optimal application. P15 cells were treated with 0, $10 \mathrm{nM}, 100 \mathrm{nM}, 1 \mu \mathrm{M}, 10 \mu \mathrm{M}$ MLT respectively for $24 \mathrm{~h}$. According to CCK-8 assay, cells treated with $1 \mu \mathrm{M}$ MLT showed the highest viability (Fig. S2a). Consistently, as evaluated by Western blot, the expression of autophagy-related proteins including Atg7, Beclin-1 and LC3-II were significantly higher while p62 was lower in cells treated with $1 \mu \mathrm{M}$ MLT, collectively suggesting a higher autophagy level in the $1 \mu \mathrm{M}$ MLTtreated group (Fig. S2b, c). The expression of senescence-related proteins was evaluated by qRT-PCR. The expression of p16, p21 and $\mathrm{y}-\mathrm{H} 2 \mathrm{AX}$ was lower when treated with $1 \mu \mathrm{M} \mathrm{MLT}$, while the expression of p53 showed no significant difference in cells treated with $100 \mathrm{nM}$ and $1 \mu \mathrm{M}$ MLT (Fig. S2d). Taken together, in order to achieve preeminent cell viability, better autophagy restoration and rejuvenation effect, we here chose $1 \mu \mathrm{M}$ MLT for further studies.

After supplemented with MLT, SA- $\beta$-gal staining was employed to investigate the effect of MLT in cellular senescence. The increased SA- $\beta$-gal positive cells in P7 and P15 cells compared to P2 cells drastically decreased after MLT treatment (Fig. 3a, b). In consist with SA- $\beta$-gal staining, increased expression of p16, p21 and p53 in P7 and P15 PDLCSs declined after MLT treatment as evaluated by Western blot (Fig. 3c, d), collectively suggesting the rejuvenation effect of MLT in senescent PDLSCs.

To detect the alteration in autophagic flux after MLT treatment, adenovirus mRFP-GFP-LC3 was transfected into P15 cells $24 \mathrm{~h}$ before MLT treatment. MLT was supplemented into basal medium for $24 \mathrm{~h}$ while Baf was added $4 \mathrm{~h}$ before tests. As shown in the merged image, the number of both red puncta and total puncta prominently elevated after MLT treatment, while the Baf treatment could further increase the autophagosomes accumulation (yellow puncta) in senescent cells with MLT treatment (Fig. 4a). These observations suggested promoted fusion of autophagosomes and lysosomes, inferring propelled lysosome-based autophagosome degradation. As for the amount of LC3-II evidenced by Western blot and flow cytometry, MLT could increase the expression of LC3-II in P15 cells, while the amount of LC3-II in MLT treated cells further increased after incubated with Baf, suggesting that the former impeded autophagic flux in P15 cells could be restored after MLT treatment (Fig. 4b, c). The expression of Atg7, Beclin-1 and p62 was evaluated by Western blot. As shown in the blots, the defective expression of Atg7 and Beclin-1 in P7 and P15 cells significantly elevated after MLT treatment, while the accumulated p62 in P7 and P15 cells decreased after MLT treatment (Fig. 4d). These results collectively suggested that MLT treatment could restore autophagy in senescent cells, which may consequently ameliorate the cellular 
senescence. In short, MLT treatment could restore autophagy and attenuate senescence features in senescent cells.

\section{4 | Inhibited autophagy deteriorates cellular senescence}

In order to explore if the rejuvenation effect by MLT was through autophagy regulation, we supplemented a widely used autophagy inhibitor 3-MA to reverse the rescued autophagy in MLT-treated P15 cells. As verified by adenovirus mRFP-GFP-LC3 transfection, 3-MA could further inhibit impaired autophagy in senescent cells. What's more, the red puncta (autolysosomes) in MLT-treated P15 cells significantly decreased after 3-MA treatments (Fig. 5a, b). As shown in Western blot analysis, the expression of autophagy-related proteins including Atg7, Beclin-1, LC3-II declined, while p62 was stacked after 3-MA single treatment compared to the control group. 3-MA treatment also abrogated the restored autophagy mediated by MLT, evidenced by Western blot analysis (Fig. 5c, d). These results collectively indicated that 3-MA could successfully impede the MLT-restored autophagy.

With impeded autophagy caused by 3-MA, the senescence-associated alteration was deteriorated. With the existence of MLT, 3-MA treatment increased the number of SA- $\beta$-gal positive cells (Fig. $5 \mathrm{e}$ ). Accordingly, the expression of senescence-related proteins p16, p21, p53 and $\mathrm{\gamma}-\mathrm{H} 2 \mathrm{AX}$ further increased with 3-MA treatment, even with the MLT treatment (Fig. $5 f, g$ ), indicating aggravated arrest of cell cycle and DNA damage along with impaired autophagy. Taken together, loss of autophagy could further exacerbate the senescence-associated features and deter the MLT-induced amelioration of senescence.

\section{5 | MLT receptor (MT) is involved in MLT-mediated autophagy regulation}

To determine whether MLT-mediated autophagy regulation was in a receptor-dependent pathway, luzindole (LUZ) was supplemented as a non-selective antagonist of MT $24 \mathrm{~h}$ ahead of tests. As shown in the adenovirus mRFP-GFP-LC3 transfected cells, red puncta in LUZ-treated cells decreased compared to the control group, while the increased red puncta mediated by MLT was also hindered by LUZ treatment (Fig. 6a, b), suggesting the restored autophagic flux was re-suppressed by LUZ treatment. Consistently, the reverted expression of autophagy-related proteins including Atg7, Beclin-1, LC3-II and p62 with MLT and LUZ simultaneous treatment compared to MLT treated group suggested that MLT restored autophagy in senescent PDLSCs in an MT-dependent way (Fig. 6c, d). As evaluated by SA- $\beta$-gal staining (Fig. 6e) and Western blot for senescence-associated proteins including p16, p21, p53 and $\mathrm{Y}$-H2AX (Fig. 6f), the senescence features of P15 cells were deteriorated when LUZ blocked MT with or without MLT treatment.

Next, we explored the possible downstream signaling pathway in this receptor-involved MLT-mediated autophagy regulation. As suggested in previous study, MT is involved in the down-regulation of the $\mathrm{PI} 3 \mathrm{~K} / \mathrm{AKT}$ by MLT, while the PI3K/AKT/mTOR pathway is recognized as a main signaling of autophagy regulation. Hence we here tested the expression of phosphorylated form of PI3K/AKT/mTOR in cells treated with LUZ. As evaluated by Western blot, the expression of p-PI3K, p-AKT and p-mTOR in LUZ- 
treated group significantly increased compared to the control group, while it had little effect on the total protein expression of PI3K, AKT and mTOR. It also suggested that MLT treatment could elevate the expression of p-PI3K, p-AKT and p-mTOR while the treatment had no effect on the total protein expression. What's more, the expression of both phosphorylated and total proteins of PI3K, AKT and mTOR was comparable between the control group and MLT and LUZ co-treated group (Fig. S3a-d). In accordance with a former study [29], these results collective suggested that MLT could negatively regulate $\mathrm{PI} 3 \mathrm{~K} / \mathrm{AKT} / \mathrm{mTOR}$ pathway via $\mathrm{MT}$.

\section{6 | MLT restores autophagy and attenuates cellular senescence by down-regulating the MT/PI3K/Akt/mTOR signaling pathway}

To further verify the MT/PI3K/Akt/mTOR pathway in MLT-regulated cellular autophagy and rejuvenation, we added MT specified blocker LUZ, PI3K/Akt agonist SC79 as well as MTOR selective agonist MHY1485 into MLT-involved treatment. Compared to MLT-treated group, the autophagic flux was obstructed in MLT + LUZ group, MLT + SC79 group and MLT + MHY1485 group, suggested by the decreased red puncta in the merged pictures of adenovirus mRFP-GFP-LC3 transfected cells (Fig. 7a). The consistent result was also shown in the expression of autophagy-associated proteins including Atg7, Beclin-1, LC3-II and p62 evaluated by Western blot (Fig. 7b, c). These results all suggested that the inducible effect of MLT for autophagy in senescent cells was regressively abrogated when using the MT blocker, PI3K/Akt agonist and mTOR agonist respectively, indicating the involvement of MT/PI3K/Akt/mTOR in MLT-mediated autophagy restoration. Along with the regressively inhibited autophagy, the attenuated senescence features mediated by MLT were consequently deteriorated in MLT + LUZ group, MLT + SC79 group and MLT + MHY1485 group, as evidenced by the increased number of SA- $\beta$-gal + cells (Fig. 8a, b), and augmented expression of senescence associated proteins including p16, p21, p53 and y-H2AX (Fig. 8c, d), indicating the down-regulation of autophagy via MT/PI3K/AKT/mTOR signaling deteriorated senescence in cells undergone long-term ex-vivo passaging.

\section{4 | Discussion}

To bridge the gap between limited number of acquirable stem cells from donors and the large quantity of stem cells that are needed for tissue engineering, it is necessary to apply long-term in-vitro passaging for cell large-scale production, especially in autologous MSC transplantation [3]. However, accumulating evidence suggested that long-term passaging might cause cellular senescence, with unexpected alterations including anomalous morphology [8], hindered proliferation capacity [35], decreased differentiation potential including chondrogenesis and osteogenesis [36]. To avoid the senescenceassociated alterations, the passage 2 to passage 5 cells, which were believed to be possessed with analogical capacity in self-renewal and differentiation, were often chosen as objective of study in numbers of studies. What's more, one research suggested that the stemness of MSCs could only be retained up to 6 passages, and significantly declined after 10 passages [37]. Another study suggested that the proliferation, differentiation and immunomodulation functions of mouse bone marrow-derived 
MSCs decreased after 15 passages [26]. Here, we chose P2 cells as young group, P7 and P15 cells as senescent group to study the senescence-associated alteration along with long-term in-vitro expansion. In consistent with previous investigations, our study reported that in PDLSCs, long-term in-vitro expansion led to senescence evidenced by increased SA- $\beta$-gal activity, elevated expression of senescence-associated proteins p16, p21 p53 and y-H2AX, which symbolized arrested cell cycle and DNA damage.

In order to overcome the challenge of accompanied senescence during in-vitro passaging, it's prerequisite to find the mechanism in lone-term expansion-caused senescence. It has been revealed that hindered autophagy was concomitant with age-related disorders [38, 39], organismal aging [40], and also senescent stem cells [12-13]. Furthermore, inhibition of autophagy could accelerate neurodegenerative disease by accumulating disease-causing aggregate-prone proteins [41] and also induce kidney damage in aging mice [42]. These results indicted indivisible relationship between autophagy and senescence. To our knowledge, the autophagy level of senescent stem cells after long-term passaging has hardly been tested before. In consistent with physiological or disease-related organismal and cellular senescence, a decline in basal autophagy was firstly found in long-term in-vitro expansion-caused cellular senescence in our study, as evidenced by impeded autophagic flux, prohibited expression of autophagy-related proteins including Atg7, Beclin-1 and LC3-II and accumulated autophagy substrate p62. To further verify the connection between autophagy alteration and cellular senescence, autophagy inhibitor 3-MA was supplemented. We found that 3-MA-mediated autophagy inhibition could deteriorate the accumulation of senescence, evidenced by elevated SA- $\beta$-gal capacity, worsened DNA damage and arrested cell cycle, suggesting hindered autophagy could deteriorate cellular senescence. On the contrary, previous study has found that the restored autophagy could alleviate the senescent status and reach functionally improvement. Pharmaceutical treatment with urolithin A to induce autophagy could improve the agerelated declined muscle function and enhance exercise capacity in old rodents [43]. The restored autophagy mediated by caloric restriction could decrease the cellular ROS level and enhance the regenerative ability of aging stem cells [44]. Stimulation of lysosomal activity to promote autophagy in the aged neural stem cells significantly enhanced their ability for neural regeneration [45]. These results collectively indicated that the regulation of autophagy could be a potential strategy for functional maintenance of senescent stem cells.

Up to now, researchers have made great effort to restore the functionality of senescent stem cells. The strategies to reach optimum cultivation for restoring or promoting capacity of stem cells can be generally divided into three categories. One is to mimic the in-vivo microenvironment and induce prior expression of cytoprotective and stemness-associated genes, including but not limited to providing an extracellular matrix (ECM)-simulated environment, and a short-term hypoxia preconditioning. Another is to utilize exogenous molecules to activate extracellular or intracellular signaling for resisting the harsh in situ microenvironment caused by ischemia, nutrition-deprivation and oxidative damage, such as pretreatments using exogenous cytokines, growth factors and other small molecule drugs. In addition, genetic strategy modulates the stem cells to acquire superior capacity in self-protection, proliferation and differentiation. Although progress has been made using former strategies, further problems have arisen. Hypoxic preconditioning was reported to give rise to arrested cell cycle and prohibited cell proliferation 
$[46,47]$. The utilization of exogenous signaling proteins seemed to have relative low efficiency and greater expense on account of their short half-life time [48]. Genetic engineering may cause the risk of insertional mutagenesis and oncogene transaction. Thus, other strategies that simultaneously prossess features of high efficiency and secured application are needed in restoring the functionality of senescent stem cells. As confirmed by recent studies, MLT exhibits unique superiority in tissue engineering. As a pleiotropic endogenous hormone secreted by pineal and almost every other tissue, MLT was confirmed to have low toxicity during treatment by both animal and clinic studies $[49,50]$. In several studies, MLT could enhance the survival stability by attenuating apoptosis, resisting oxidative stress and inflammation damage [51], improve the chondrogenesis and osteogenesis of MSCs [53], and also maintain the stemness of long-term passaged stem cells, resulting in preserved proliferation, osteogenic differentiation and immunomodulation capacity [26]. Except from the well-known role in stem cell-based therapy as a probable free radical scavenger with excellent anti-inflammation and differentiation enhancement properties, recently, researchers also found that MLT could function as a regulator for autophagy. In some studies, MLT could promote the basal levels of autophagy under physiological conditions and maintain neuronal homeostasis and survival from a subarachnoid hemorrhage followed by brain injury [53], and also modulates autophagy to attenuate the cardiac ischemia/reperfusion injury [54,55]. The property of MLT-mediated regulation of autophagy could also benefit in some age-related diseases. It was found that MLT in-vivo application ameliorated AD-induced cardiac atrophy [28], and enhanced the impeded cognitive function in tau-related AD rats [27] by restoring the autophagic flux. What's more, MLT could improve degradation of damaged mitochondria by mitophagy during aging and under neurodegenerative conditions [56]. Similar to the studies mentioned above, our study also confirmed that MLT could effectively restore the cellular autophagy not only by elevating the basal autophagy level in senescent P15 cells, but also by reinstating the autophagic level by enhancing the lysosome-dependent degradation of autophagosomes. Our study also found that restored autophagy was further accompanied with ameliorated senescence. To further clarify if it was the restored autophagy that benefited the rejuvenation effects, we found that the defective autophagy caused by the autophagy inhibitor 3-MA could consequently abrogate the MLT-mediated rejuvenation. Therefore, our study suggests that the restored autophagy alleviated cellular senescence, and the manipulation of autophagy could be an effective strategy to maintain functionality of senescent cells.

To investigate the underlying mechanism of MLT-mediated autophagy restoration, we first explored if the effect was dependent on MT. We supplemented MT-specified inhibitor LUZ into cultured cells. We found that LUZ could further exacerbate the impeded autophagy in senescent cells without MLT treatment, giving rise to aggravated cellular senescence. Even in senescent cells treated with MLT, LUZ could abrogate the inducible effect of autophagy mediated by MLT, and further inhibited the rejuvenation mediated by MLT. These results indicated that the MLT-mediated autophagy restoration was in an MTdependent manner in senescent cells. What's more, mTOR plays a role as central switch to autophagy. The inhibitory regulation of PI3K/AKT/mTOR pathway can activate autophagy and as reported, several studies chose to target PI3K/AKT/mTOR pathway for autophagy regulation in stem cells [57-59]. Accordingly, our study demonstrated that the expression of p-PI3K, p-AKT and p-mTOR significantly 
decreased after the treatment of MLT but was reversely induced to increase by LUZ treatment. We thus concluded that the MT-dependent MLT-mediated autophagy was possibly through the inhibitory regulation of the PI3K/AKT/mTOR pathway. This is in consistence with a current study, which confirmed that MLT could regulate the PI3K/AKT pathway in an inhibitory way [29].

To precisely confirm the MLT-mediated autophagy through MT/PI3K/AKT/mTOR pathway, we respectively applied LUZ, PI3K/AKT specific agonist SC79 and mTOR agonist MHY1485 with the MLT treatment, and found that the autophagy restoration and senescence attenuation effect mediated by MLT could be abrogated with blocked MT and activation of PI3K/AKT/mTOR pathway. However, our study didn't determine the exact type of MT involving in the MLT-mediated autophagy restoration, which should be our main pursue in the future.

To sum up, our study revealed that impaired autophagy was one of the vital mechanisms of cellular senescence induced by long-term ex-vivo expansion, which can be restored by MLT through MT/ $\mathrm{PI} 3 \mathrm{~K} / \mathrm{AKT} / \mathrm{mTOR}$ pathway. This work innovatively purposes a strategy that MLT treatment targeting impeded autophagy can be utilized to rejuvenate stem cells during long-term passaging. The investigation focused on the mechanism that inhibiting the PI3K/AKT/mTOR pathway could enhance autophagy to attenuate cellular senescence, which may provide possible target for the research and even clinical application aiming at the rejuvenation of stem cells for cellular therapy.

\section{5| Conclusion}

Large-scale production of cellular materials for use in a clinical setting necessitates safe and costeffective agents to rescue cell dysfunction and therapeutic failure of stem cells following long-term exvivo expansion. Although use of MLT as a cell-medium adjuvant has been proposed to prevent cells from senescence following long-term passaging, the underlying mechanism remains largely unexplored. In this study, we found that the function of MLT in combating cell aging was related to its role as an autophagy regulator. Further investigations indicated that the MT-dependent PI3K/AKT/mTOR signaling was involved in MLT-induced alteration in cell autophagy. This is the first report demonstrates that MLTinduced cell rejuvenation functioned by the regulation and restoration of damaged cell autophagic processes, pointing to a potential target for using autophagy-restoring agents to develop optimized clinical-scale cell production protocols to product adequate cellular materials for cellular therapy and regenerative medicine.

\section{Abbreviations}

MSCs: mesenchymal stromal cells; SA- $\beta$-gal: senescence-associated $\beta$-galacotosidase; ROS: reactive oxygen species; MLT: melatonin; AD: Alzheimer disease; MT: MLT receptor; PDL: periodontal ligament; PDLSCs: periodontal ligament stem cells; CCK-8: Cell Counting Kit-8; ALP: alkaline phosphatase; 3-MA: 3methyladenine; LUZ: luzindole; Baf: bafilomycin A1. 


\section{Declarations}

\section{Author contributions}

F-M C, B-M T and Y A designed the study and revised the manuscript. $Y-Z T$ and $X-Y X$ performed the experiments and wrote the manuscript. J-M D, Y Y and X-T H collected data and did the statistical analysis. Y-L Z and T-X Z prepared figures. All authors have read and approved the final submitted manuscript.

\section{Acknowledgements}

We acknowledge that the cell-based research of this study was performed at State Key Laboratory of Military Stomatology, National Clinical Research Center for Oral Diseases and Shaanxi Engineering Research Center for Dental Materials and Advanced Manufacture, FMMU.

\section{Funding}

The study was supported by the Shaanxi Key Scientific and Technological Innovation Team (2017KCT32), the National Natural Science Foundation of China (81530050, 81970947, 81991503, 81800971, 81700971 and 82001052), the National Key Research and Development Program of China (2018YFC1105204), and the Changjiang Scholars Program of the Ministry of Education of the People's Republic of China (2016)

\section{Availability of data and materials}

All data generated or analyzed during this study are included in this published article.

\section{Code availability}

All software used in this study was obtained legally, and custom code is available from the corresponding author on reasonable request.

\section{Ethics approval and consent to participate}

The experimental protocol of this study was approved by the Ethics Committee of the Stomatological Hospital of FMMU (201203), and informed consent was signed by all the subjects who donated their extracted teeth for cell isolation. 


\section{Conflict of interest}

The authors have no conficts of interest/competing interests to declare.

\section{Consent to participate/Consent for publication}

Consent to participate/consent for publication is not applicable to this study.

\section{References}

1. Davis D, Stewart D. Autologous cell therapy for cardiac repair. Expert Opin Biol Ther. 2011;11(4):489508.

2. Rigato M, Monami M, Fadini G. Autologous Cell Therapy for Peripheral Arterial Disease: Systematic Review and Meta-Analysis of Randomized, Nonrandomized, and Noncontrolled Studies. Circ Res. 2017;120(8):1326-40.

3. Toma C, Wagner W, Bowry S, Schwartz A, Villanueva F. Fate of culture-expanded mesenchymal stem cells in the microvasculature: in vivo observations of cell kinetics. Circ Res. 2009;104(3):398-402.

4. Furlani D, Li W, Pittermann E, Klopsch C, Wang L, Knopp A, et al. A transformed cell population derived from cultured mesenchymal stem cells has no functional effect after transplantation into the injured heart. Cell Transplant. 2009;18(3):319-31.

5. Bustos M, Huleihel L, Kapetanaki M, Lino-Cardenas CL, Mroz L, Ellis BM, et al. Aging mesenchymal stem cells fail to protect because of impaired migration and antiinflammatory response. Am J Respir Crit Care Med. 2014;189(7):787-98.

6. Castorina A, Szychlinska M, Marzagalli R, Musumeci G. Mesenchymal stem cells-based therapy as a potential treatment in neurodegenerative disorders: is the escape from senescence an answer? Neural regeneration research. 2015;10(6):850-8.

7. Sepúlveda J, Tomé M, Fernández M, Delgado M, Campisi J, Bernad A, et al. Cell senescence abrogates the therapeutic potential of human mesenchymal stem cells in the lethal endotoxemia model. Stem Cells. 2014;32(7):1865-77.

8. Korolchuk V, Miwa S, Carroll B, von Zglinicki T. Mitochondria in Cell Senescence: Is Mitophagy the Weakest Link? EBioMedicine 2017;21:7-13. ${ }^{1}$.

9. Ren R, Ocampo A, Liu G, Izpisua Belmonte JC. Regulation of Stem Cell Aging by Metabolism Epigenetics Cell Metab. 2017;26(3):460-74.

10. Bork S, Pfister S, Witt H, Horn P, Korn B, Ho AD, et al. DNA methylation pattern changes upon longterm culture and aging of human mesenchymal stromal cells. Aging cell. 2010;9(1):54-63.

11. Jiang T, Xu G, Wang Q, Yang L, Zheng L, Zhao J, et al. In vitro expansion impaired the stemness of early passage mesenchymal stem cells for treatment of cartilage defects. Cell Death Dis. 2017;8(6):e2851. 
12. García-Prat L, Martínez-Vicente M, Perdiguero E, Ortet L, Rodríguez-Ubreva J, Rebollo E, et al. Autophagy maintains stemness by preventing senescence. Nature. 2016;529(7584):37-42.

13. Revuelta M, Matheu A. Autophagy in stem cell aging. Aging cell. 2017;16(5):912-5.

14. Ho T, Warr M, Adelman E, Lansinger OM, Flach J, Verovskaya EV, et al. Autophagy maintains the metabolism and function of young and old stem cells. Nature. 2017;543(7644):205-10.

15. Acuña-Castroviejo D, Escames G, Venegas C, Díaz-Casado ME, Lima-Cabello E, López LC, et al. Extrapineal melatonin: sources, regulation, and potential functions. Cell Mol Life Sci. 2014;71(16):2997-3025.

16. Reiter R. Pineal melatonin: cell biology of its synthesis and of its physiological interactions. Endocr Rev. 1991;12(2):151-80.

17. Reiter R, Tan D, Galano A. Melatonin: exceeding expectations. Physiology (Bethesda). 2014;29(5):325-33.

18. Galano A, Tan D, Reiter R. Melatonin. A Versatile Protector against Oxidative DNA Damage. Molecules (Basel, Switzerland) 2018;23(3).

19. Bermejo-Millo J, Guimarães M, de Luxán-Delgado B, Potes Y, Pérez-Martínez Z, Díaz-Luis A, et al. High-Fructose Consumption Impairs the Redox System and Protein Quality Control in the Brain of Syrian Hamsters: Therapeutic Effects of Melatonin. Mol Neurobiol. 2018;55(10):7973-86.

20. Luchetti F, Canonico B, Bartolini D, Arcangeletti M, Ciffolilli S, Murdolo G, et al. Melatonin regulates mesenchymal stem cell differentiation: a review. J Pineal Res. 2014;56(4):382-97.

21. Wu Z, Qiu X, Gao B, Lian C, Peng Y, Liang A, et al. Melatonin-mediated miR-526b-3p and miR-590-5p upregulation promotes chondrogenic differentiation of human mesenchymal stem cells. J Pineal Res. 2018;65(1):e12483.

22. Zhou L, Chen X, Liu T, Gong Y, Chen S, Pan G, et al. Melatonin reverses H2O2-induced premature senescence in mesenchymal stem cells via the SIRT1-dependent pathway. J Pineal Res. 2015;59(2):190-205.

23. Shuai Y, Liao L, Su X, et al. Melatonin Treatment Improves Mesenchymal Stem Cells Therapy by Preserving Stemness during Long-term In Vitro Expansion. Theranostics 2016;6(11):1899-1917.

24. Pierpaoli W, Dall'Ara A, Pedrinis E, Regelson W. The pineal control of aging. The effects of melatonin and pineal grafting on the survival of older mice. Ann N Y Acad Sci. 1991;621:291-313.

25. Thomas J, Smith-Sonneborn J. Supplemental melatonin increases clonal lifespan in the protozoan Paramecium tetraurelia. J Pineal Res. 1997;23(3):123-30.

26. Kedziora-Kornatowska K, Szewczyk-Golec K, Czuczejko J, van Marke de Lumen K, Pawluk H, Motyl J, et al. Effect of melatonin on the oxidative stress in erythrocytes of healthy young and elderly subjects. J Pineal Res. 2007;42(2):153-8.

27. Luengo E, Buendia I, Fernández-Mendívil C, Trigo-Alonso P, Negredo P, Michalska P, et al. Pharmacological doses of melatonin impede cognitive decline in tau-related Alzheimer models, once tauopathy is initiated, by restoring the autophagic flux. J Pineal Res. 2019;67(1):e12578. 
28. Wang S, Wang L, Qin X, Turdi S, Sun D, Culver B, et al. ALDH2 contributes to melatonin-induced protection against APP/PS1 mutation-prompted cardiac anomalies through cGAS-STING-TBK1mediated regulation of mitophagy. Signal transduction targeted therapy. 2020;5(1):119.

29. Li Z, Li X, Chen C, Chan MTV, Wu WKK, Shen J, et al. Melatonin inhibits nucleus pulposus (NP) cell proliferation and extracellular matrix (ECM) remodeling via the melatonin membrane receptors mediated PI3K-Akt pathway. J Pineal Res 2017;63(3).

30. Janku F, McConkey D, Hong D, Kurzrock R. Autophagy as a target for anticancer therapy. Nature reviews Clinical oncology. 2011;8(9):528-39.

31. Wallroth $A$, Koch $P$, Marat $A$, Krause E, Haucke V. Protein kinase $\mathrm{N}$ controls a lysosomal lipid switch to facilitate nutrient signalling via mTORC1. Nat Cell Biol. 2019;21(9):1093-101.

32. Wu RX, Bi CS, Yu Y, Zhang LL, Chen FM. Age-related decline in the matrix contents and functional properties of human periodontal ligament stem cell sheets. Acta biomaterialia. 2015;22:70-82.

33. Li X, Zhang B, Wang H, Zhao X, Zhang Z, Ding G, et al. The effect of aging on the biological and immunological characteristics of periodontal ligament stem cells. Stem Cell Res Ther. 2020;11(1):326.

34. Dimri G, Lee X, Basile G, Acosta M, Scott G, Roskelley C, et al. A biomarker that identifies senescent human cells in culture and in aging skin in vivo. Proc Natl Acad Sci U S A. 1995;92(20):9363-7.

35. Stolzing A, Jones E, McGonagle D, Scutt A. Age-related changes in human bone marrow-derived mesenchymal stem cells: consequences for cell therapies. Mech Ageing Dev. 2008;129(3):163-73.

36. Shen C, Jiang T, Zhu B, Le Y, Liu J, Qin Z, et al. In vitro culture expansion impairs chondrogenic differentiation and the therapeutic effect of mesenchymal stem cells by regulating the unfolded protein response. J Biol Eng. 2018;12:26.

37. Gharibi B, Hughes F. Effects of medium supplements on proliferation, differentiation potential, and in vitro expansion of mesenchymal stem cells. Stem cells translational medicine. 2012;1(11):771-82.

38. Levine B, Kroemer G. Autophagy in the pathogenesis of disease. Cell. 2008;132(1):27-42.

39. Dikic I, Elazar Z. Mechanism and medical implications of mammalian autophagy. Nature reviews Molecular cell biology. 2018;19(6):349-64.

40. Hansen $M$, Rubinsztein $D$, Walker $D$. Autophagy as a promoter of longevity: insights from model organisms. Nature reviews Molecular cell biology. 2018;19(9):579-93.

41. Cullup T, Kho A, Dionisi-Vici C, Brandmeier B, Smith F, Urry Z, et al. Recessive mutations in EPG5 cause Vici syndrome, a multisystem disorder with defective autophagy. Nat Genet. 2013;45(1):83-7.

42. Yamamoto T, Takabatake Y, Kimura T, Takahashi A, Namba T, Matsuda J, et al. Time-dependent dysregulation of autophagy: Implications in aging and mitochondrial homeostasis in the kidney proximal tubule. Autophagy. 2016;12(5):801-13.

43. Ryu D, Mouchiroud L, Andreux P, Katsyuba E, Moullan N, Nicolet-Dit-Félix AA, et al. Urolithin A induces mitophagy and prolongs lifespan in C. elegans and increases muscle function in rodents. Nat Med. 2016;22(8):879-88. 
44. Bi S, Wang $\mathrm{H}$, Kuang $\mathrm{W}$. Stem cell rejuvenation and the role of autophagy in age retardation by caloric restriction: An update. Mech Ageing Dev. 2018;175:46-54.

45. Audesse A, Webb A. Enhancing Lysosomal Activation Restores Neural Stem Cell Function During Aging. J Exp Neurosci. 2018;12:1179069518795874.

46. Eliasson P, Rehn M, Hammar P, Larsson P, Sirenko O, Flippin LA, et al. Hypoxia mediates low cell-cycle activity and increases the proportion of long-term-reconstituting hematopoietic stem cells during in vitro culture. Exp Hematol. 2010;38(4):301-10.e302.

47. Guitart A, Hammoud M, Dello Sbarba P, Ivanovic Z, Praloran V. Slow-cycling/quiescence balance of hematopoietic stem cells is related to physiological gradient of oxygen. Exp Hematol. 2010;38(10):847-51.

48. Chen FM, Shelton RM, Jin Y, Chapple IL. Localized delivery of growth factors for periodontal tissue regeneration: role, strategies, and perspectives. Med Res Rev. 2009;29(3):472-513.

49. Jahnke G, Marr M, Myers C, Wilson R, Travlos G, Price C. Maternal and developmental toxicity evaluation of melatonin administered orally to pregnant Sprague-Dawley rats. Toxicol Sci. 1999;50(2):271-9.

50. Sánchez-Barceló E, Mediavilla M, Tan D, Reiter RJ. Clinical uses of melatonin: evaluation of human trials. Curr Med Chem. 2010;17(19):2070-95.

51. Lee MS, Yin TC, Sung PH, Chiang JY, Sun CK, Yip HK. Melatonin enhances survival and preserves functional integrity of stem cells: A review. J Pineal Res 2017;62(2).

52. Gao B, Gao W, Wu Z, Zhou T, Qiu X, Wang X, et al. Melatonin rescued interleukin 1ß-impaired chondrogenesis of human mesenchymal stem cells. Stem Cell Res Ther. 2018;9(1):162.

53. Chen J, Wang L, Wu C, Hu Q, Gu C, Yan F, et al. Melatonin-enhanced autophagy protects against neural apoptosis via a mitochondrial pathway in early brain injury following a subarachnoid hemorrhage. J Pineal Res. 2014;56(1):12-9.

54. Zhou H, Li D, Zhu P, Hu S, Hu N, Ma S, et al. Melatonin suppresses platelet activation and function against cardiac ischemia/reperfusion injury via PPARY/FUNDC1/mitophagy pathways. J Pineal Res 2017;63(4).

55. Zhang $Y$, Wang $Y, X u J$, Tian F, Hu S, Chen $Y$, et al. Melatonin attenuates myocardial ischemiareperfusion injury via improving mitochondrial fusion/mitophagy and activating the AMPK-OPA1 signaling pathways. J Pineal Res. 2019;66(2):e12542.

56. Fujikake N, Shin M, Shimizu S. Association Between Autophagy and Neurodegenerative Diseases. Front Neurosci. 2018;12:255.

57. Xu Y, Tan M, Ma X, Li H, He X, Chen Z, et al. Human mesenchymal stem cells-derived conditioned medium inhibits hypoxia-induced death of neonatal porcine islets by inducing autophagy. Xenotransplantation. 2020;27(1):e12556.

58. Wang $M$, Liang $X$, Cheng $M$, Yang L, Liu $H$, Wang $X$, et al. Homocysteine enhances neural stem cell autophagy in in vivo and in vitro model of ischemic stroke. Cell Death Dis. 2019;10(8):561. 
59. Wu Z, Lu H, Yao J, Zhang X, Huang Y, Ma S, et al. GABARAP promotes bone marrow mesenchymal stem cells-based the osteoarthritis cartilage regeneration through the inhibition of $\mathrm{PI} 3 \mathrm{~K} / \mathrm{AKT} / \mathrm{mTOR}$ signaling pathway. J Cell Physiol. 2019;234(11):21014-26.

\section{Figures}

A
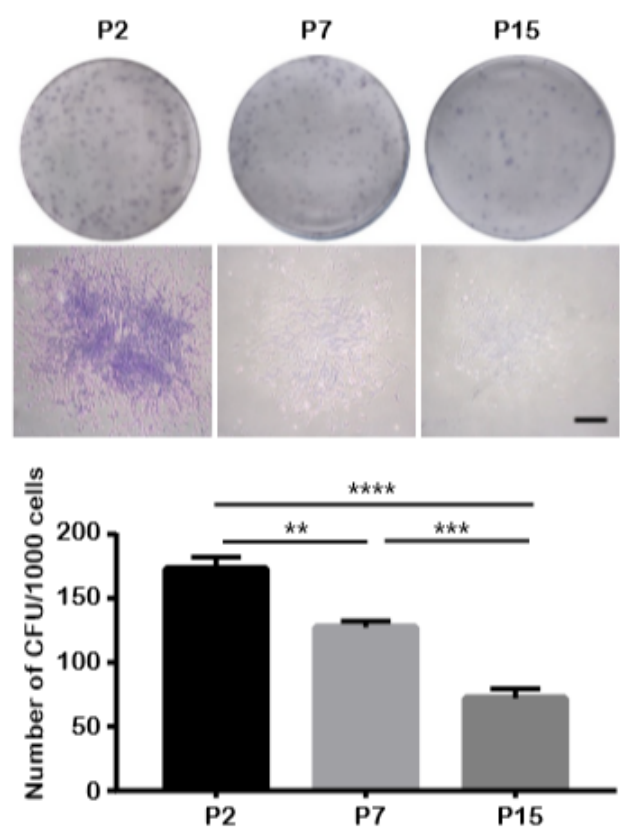

C
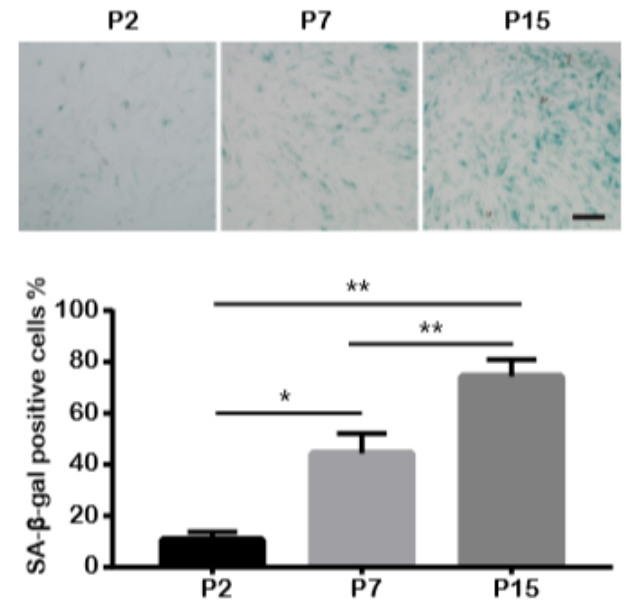

B

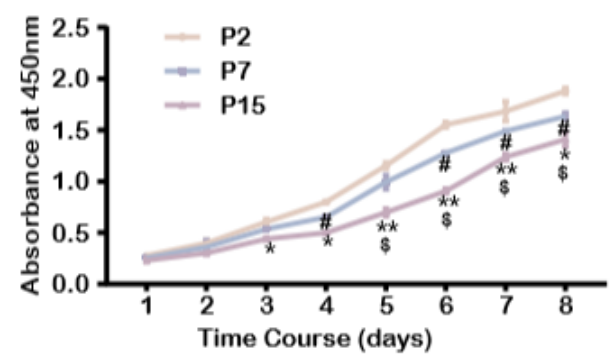

D
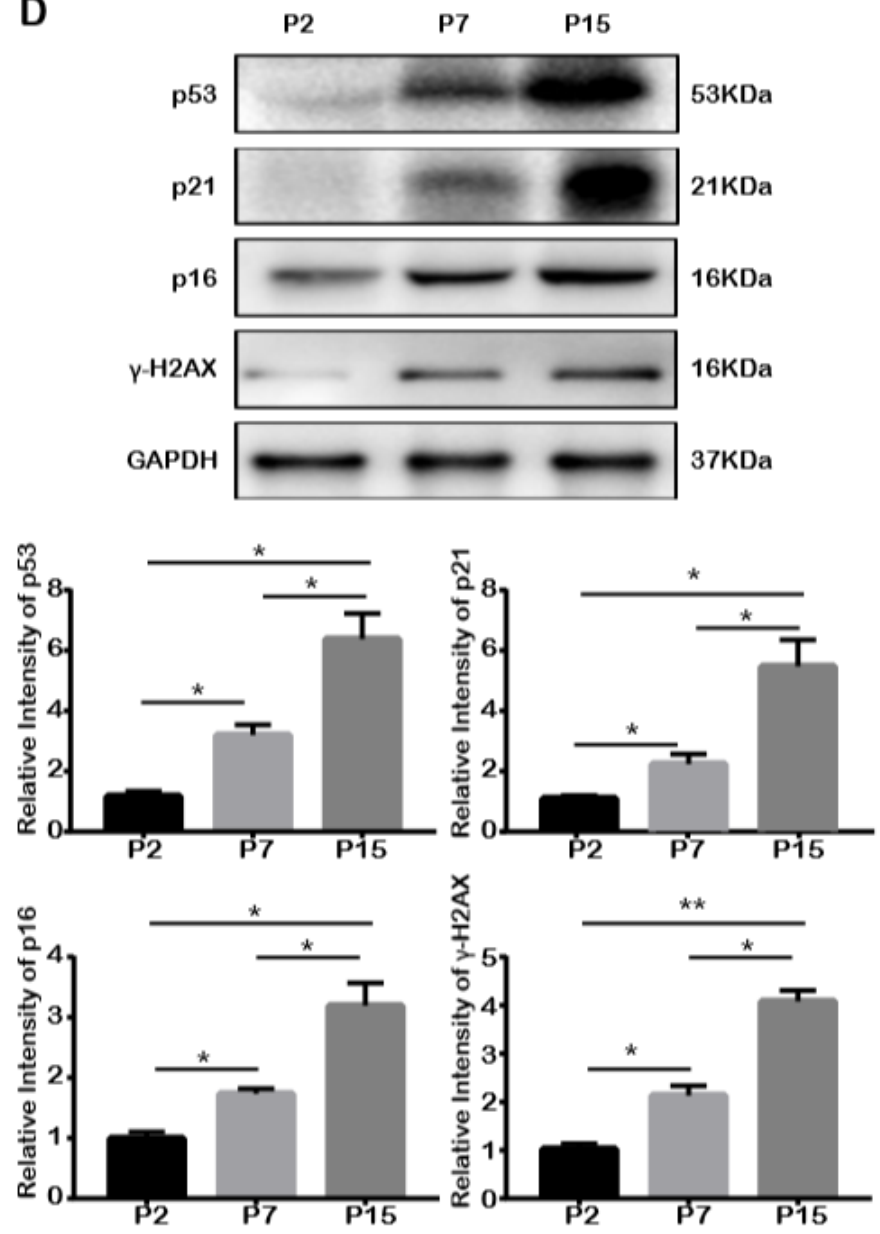

Figure 1 
Long-term ex-vivo culture causes senescence in human PDLSCs. Human PDLSCs were cultured and passaged in-vitro; across the ex-vivo expansion stage, passage 2 (P2), passage 7 (P7), and passage 15 (P15) cells were respectively collected for the following examinations. ${ }^{*} p<0.05,{ }^{* *} p<0.01, * \star * p<0.001$ and $* \star \star * p<0.0001$ represent significant differences between the indicated columns. (a) Colony-forming ability of PDLSCs changed during long-term ex-vivo expansion. (Top: General views of the cell colonies formed by P2, P7 and P15 cells and a representative singly colony from the top panel (scale bar $=100$ $\mu \mathrm{m})$; Bellow: Quantitative analysis of cell colonies formed by P2, P7 and P15 cells). (b) Proliferative activity of P2, P7 and P15 cells in terms of CCK-8 assay (P2 v.s. P15: ${ }^{*}<0.05$ and ${ }^{\star \star} p<0.01 ; P 2$ v.s. P7: $\# p<0.05$; P7 v.s. P15: $\$ p<0.05$ ). (c) SA- $\beta$-gal in P2, P7 and P15 cells. (Top: Representative images of SA- $\beta$-gal expression in P2, P7 and P15 cells (immunocytochemical staining, positive stained cells were dyed in blue; scale bar $=100 \mu \mathrm{m})$; Bellow: Percentage of the SA- $\beta$-gal positive cells out of the total number of cells and quantitative analysis). (d) Cell senescence-related proteins in P2, P7 and P15 cells. (Top: Protein levels of p53, p21, p16 and $\mathrm{Y}-\mathrm{H} 2 \mathrm{AX}$ in terms of Western blot assay; Bellow: Quantitative analysis of p53, p21, p16 and $y-H 2 A X$ expressions in P2, P7 and P15 cells). 
A
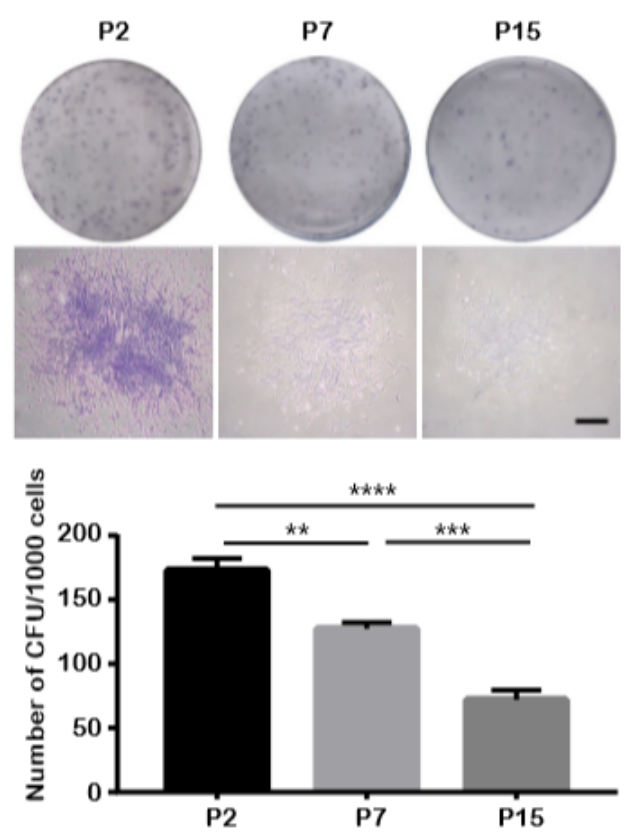

C
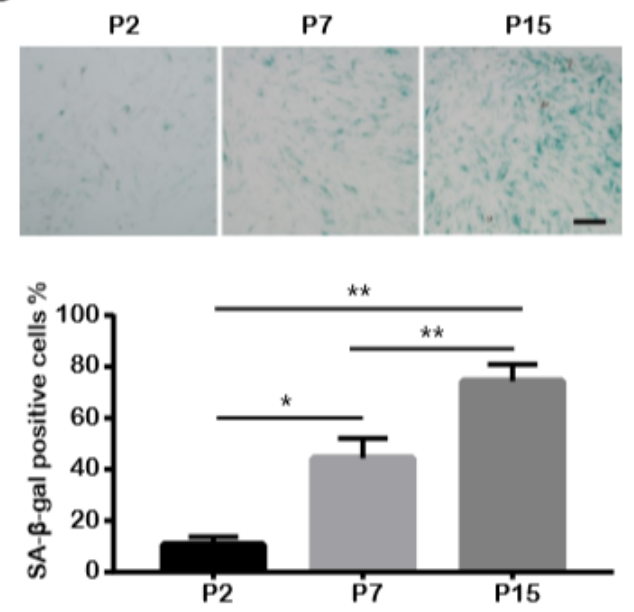

B

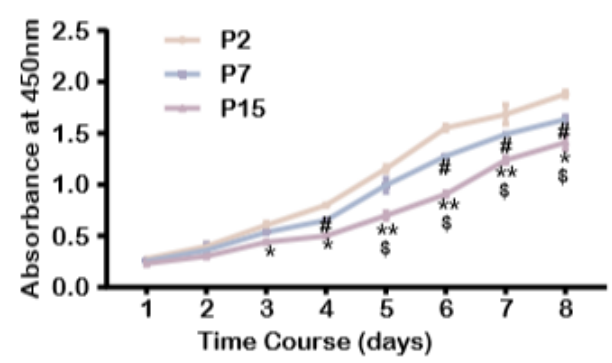

D
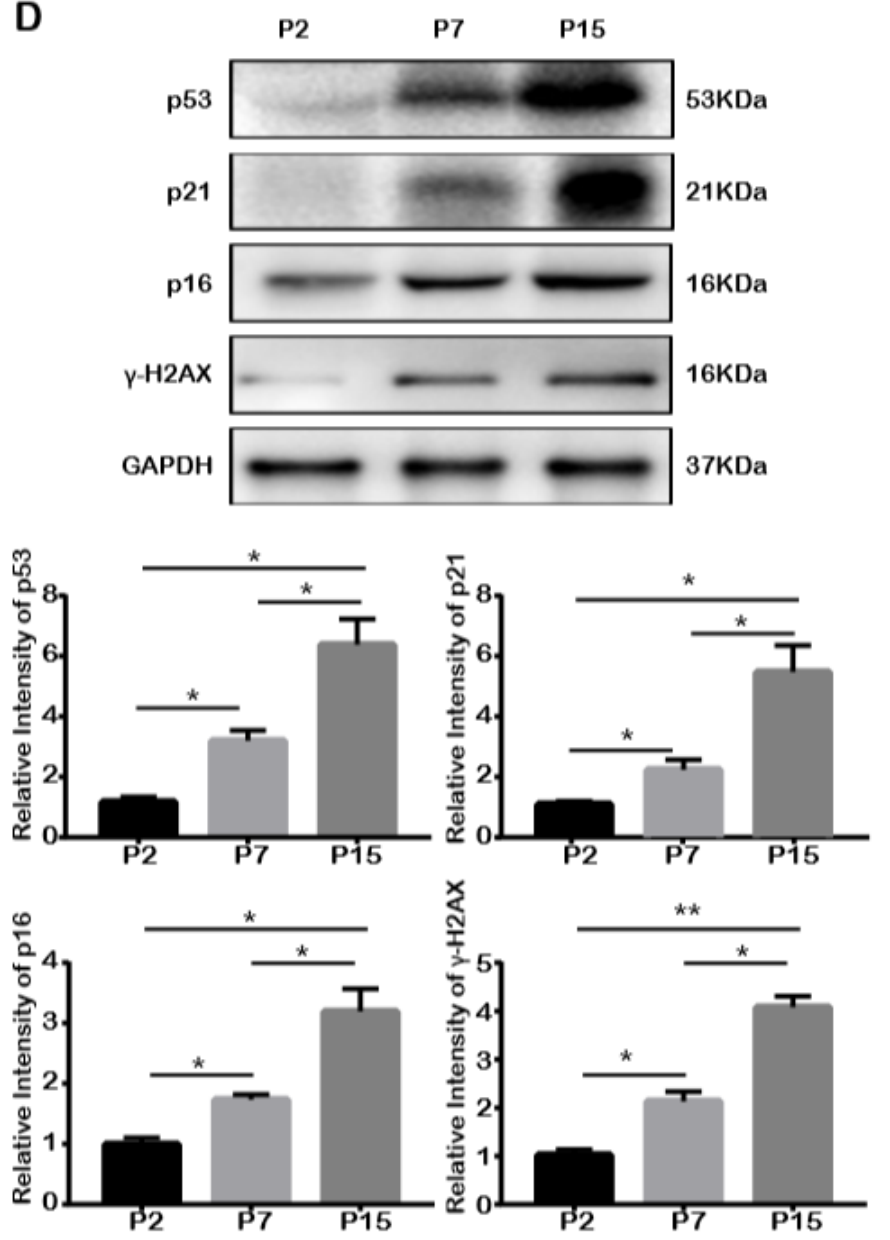

\section{Figure 1}

Long-term ex-vivo culture causes senescence in human PDLSCs. Human PDLSCs were cultured and passaged in-vitro; across the ex-vivo expansion stage, passage 2 (P2), passage 7 (P7), and passage 15 (P15) cells were respectively collected for the following examinations. ${ }^{*} p<0.05,{ }^{* *} p<0.01,{ }^{* *} p<0.001$ and $* * \star * p<0.0001$ represent significant differences between the indicated columns. (a) Colony-forming ability of PDLSCs changed during long-term ex-vivo expansion. (Top: General views of the cell colonies formed by P2, P7 and P15 cells and a representative singly colony from the top panel (scale bar $=100$ 
$\mu \mathrm{m})$; Bellow: Quantitative analysis of cell colonies formed by P2, P7 and P15 cells). (b) Proliferative activity of P2, P7 and P1 5 cells in terms of CCK-8 assay (P2 v.s. P15: ${ }^{*}<0.05$ and ${ }^{*} p<0.01 ; P 2$ v.s. P7: $\# p<0.05$; P7 v.s. P15: $\$ p<0.05$ ). (c) SA- $\beta$-gal in P2, P7 and P15 cells. (Top: Representative images of SA- $\beta$-gal expression in P2, P7 and P15 cells (immunocytochemical staining, positive stained cells were dyed in blue; scale bar $=100 \mu \mathrm{m}$ ); Bellow: Percentage of the SA- $\beta$-gal positive cells out of the total number of cells and quantitative analysis). (d) Cell senescence-related proteins in P2, P7 and P15 cells. (Top: Protein levels of p53, p21, p16 and $\mathrm{Y}-\mathrm{H} 2 \mathrm{AX}$ in terms of Western blot assay; Bellow: Quantitative analysis of p53, p21, p16 and $\mathrm{y}-\mathrm{H} 2 \mathrm{AX}$ expressions in P2, P7 and P15 cells).

A
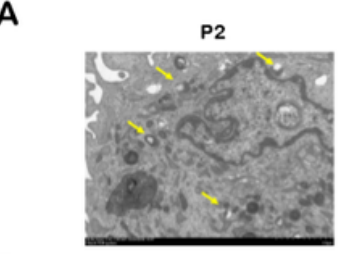

B

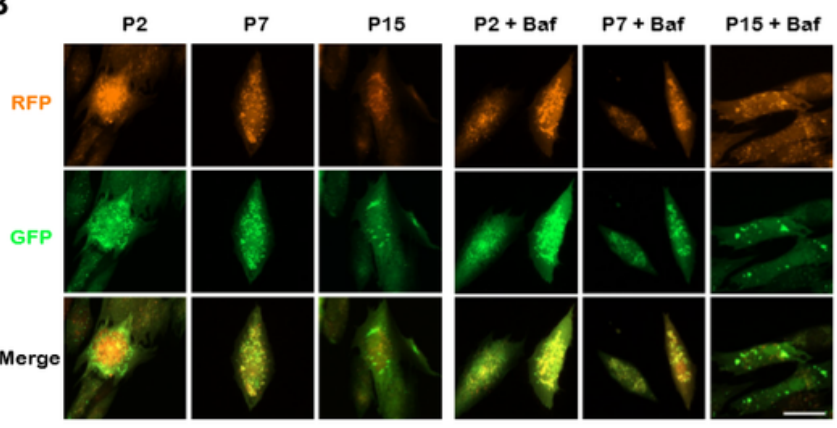

C
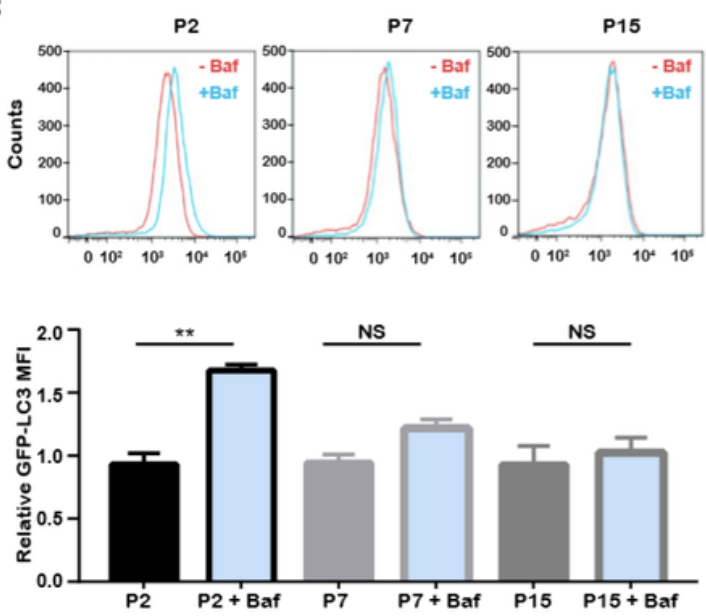

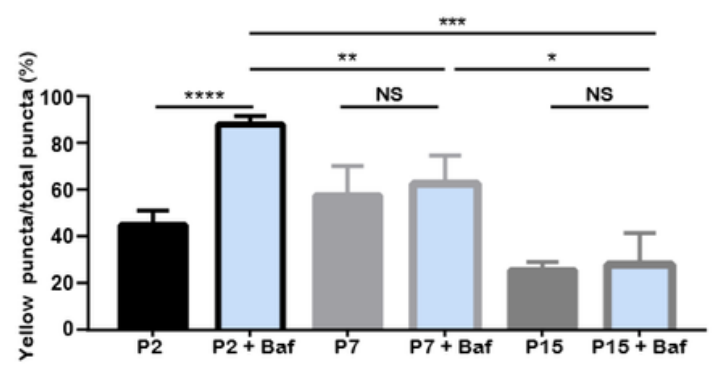

E

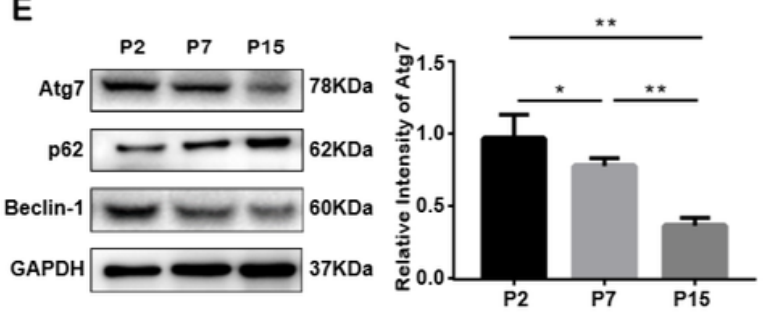

D
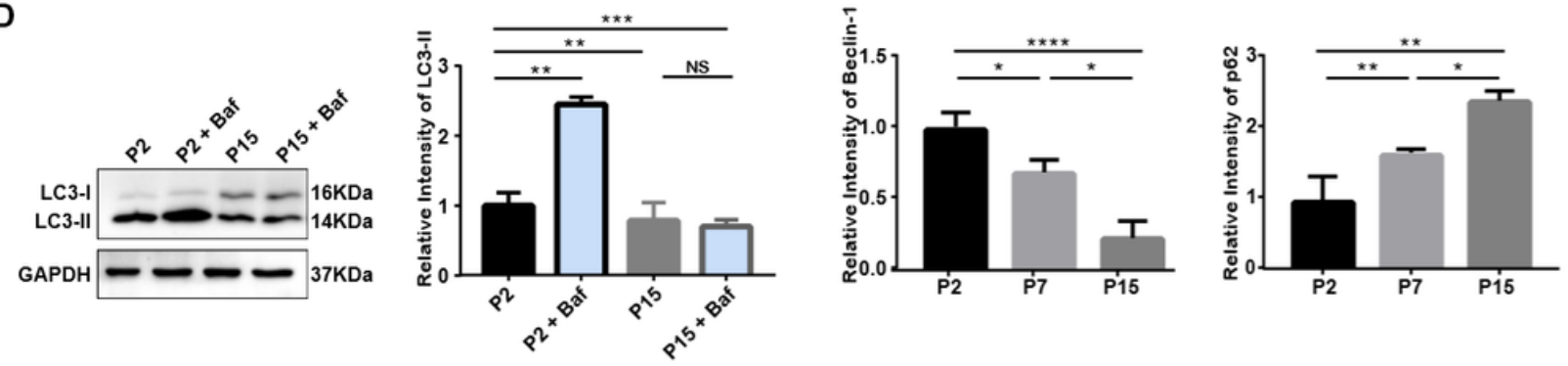

\section{Figure 2}

Long-term ex-vivo culture causes defective autophagy in human PDLSCs. * $p<0.05,{ }^{\star *} p<0.01$, *** $p<$ 0.001 and $\star * \star \star p<0.0001$ represent significant differences between the indicated columns, while NS represents no significant difference. (a) Electron microscopy images of P2, P7 and P15 cells. Arrowheads 
indicate autophagic vesicles. Scale bars, $2 \mu \mathrm{m}$. (b) Presence of autophagosomes (yellow) and their maturation into autolysosomes (red) in adenovirus mRFP-GFP-LC3-transfected cells (P2, P7, P15) with or without Baf treatment (Top: Representative confocal images, scale bar $=50 \mu \mathrm{m}$, magnification, 200x; Bellow: Quantitative analysis for the percentage of the yellow puncta out of the total puncta based on confocal examination). (c) GFP-LC3 fluorescence levels in P2, P7, P15 cells before and after Baf treatment. (Top: Representative flow cytometry graphs; Bellow: Quantitative analysis for MFI of GFPLC3). (d) LC3-II levels in P2 and P15 cells before and after Baf treatment. (Left: Protein levels of LC3-II in terms of Western blot assay; Right: Quantitative analysis of cell LC3-II expressions). (e) Cell autophagyrelated proteins in P2, P7 and P15 cells in terms of Western blot assay and quantitative analysis of Atg7, p62 and Beclin-1 expressions.

A

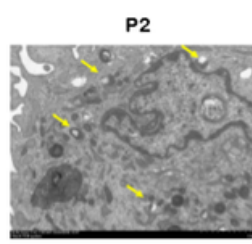

B

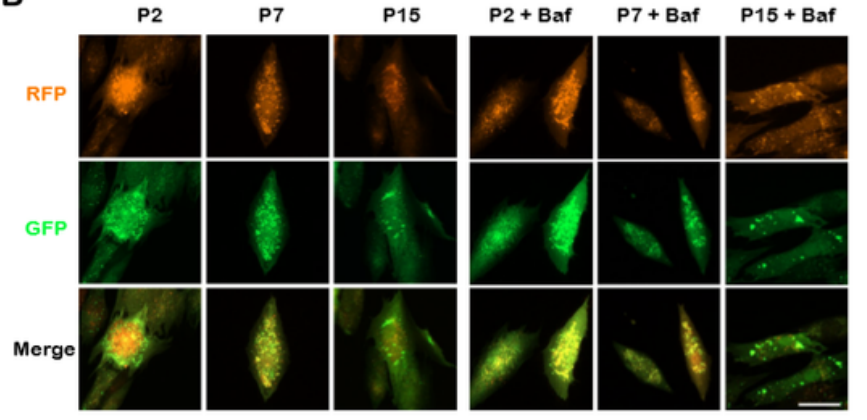

C
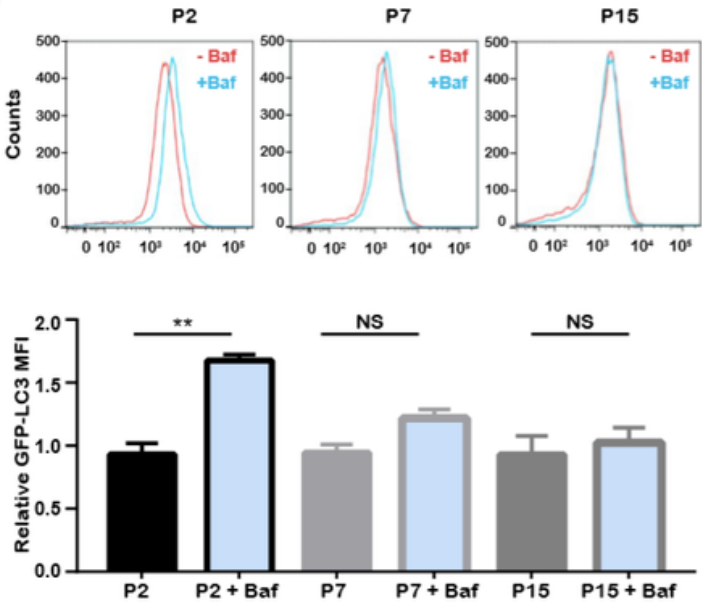

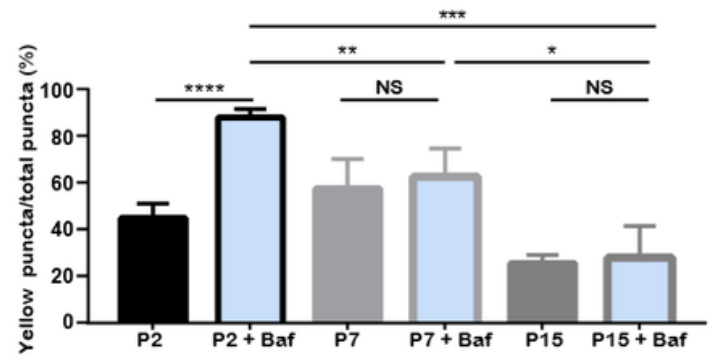

D

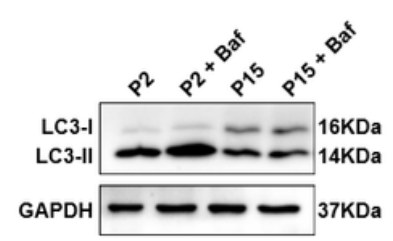

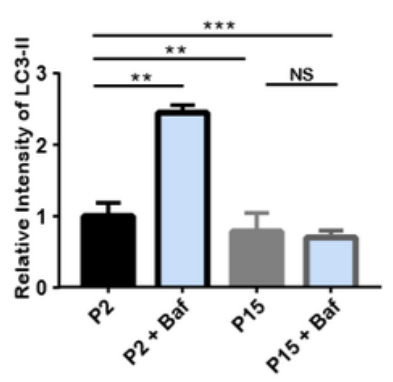

E
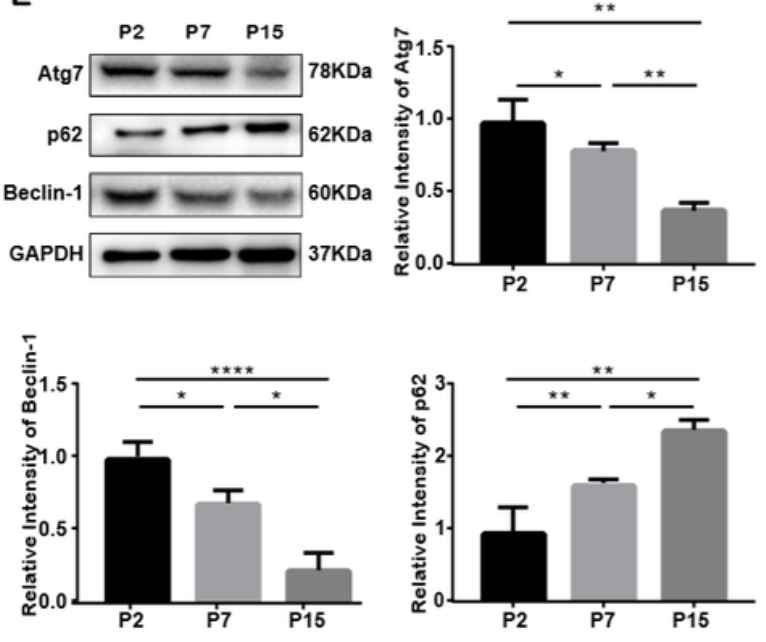

Figure 2 
Long-term ex-vivo culture causes defective autophagy in human PDLSCs. ${ }^{*} p<0.05,{ }^{\star \star} p<0.01, * \star \star p<$ 0.001 and $* \star * \star p<0.0001$ represent significant differences between the indicated columns, while NS represents no significant difference. (a) Electron microscopy images of P2, P7 and P15 cells. Arrowheads indicate autophagic vesicles. Scale bars, $2 \mu \mathrm{m}$. (b) Presence of autophagosomes (yellow) and their maturation into autolysosomes (red) in adenovirus mRFP-GFP-LC3-transfected cells (P2, P7, P15) with or without Baf treatment (Top: Representative confocal images, scale bar $=50 \mu \mathrm{m}$, magnification, 200x; Bellow: Quantitative analysis for the percentage of the yellow puncta out of the total puncta based on confocal examination). (c) GFP-LC3 fluorescence levels in P2, P7, P15 cells before and after Baf treatment. (Top: Representative flow cytometry graphs; Bellow: Quantitative analysis for MFI of GFPLC3). (d) LC3-II levels in P2 and P15 cells before and after Baf treatment. (Left: Protein levels of LC3-II in terms of Western blot assay; Right: Quantitative analysis of cell LC3-Il expressions). (e) Cell autophagyrelated proteins in P2, P7 and P15 cells in terms of Western blot assay and quantitative analysis of Atg7, p62 and Beclin-1 expressions. 
A

P2

P7

P7 + MLT

P15

P15 + MLT
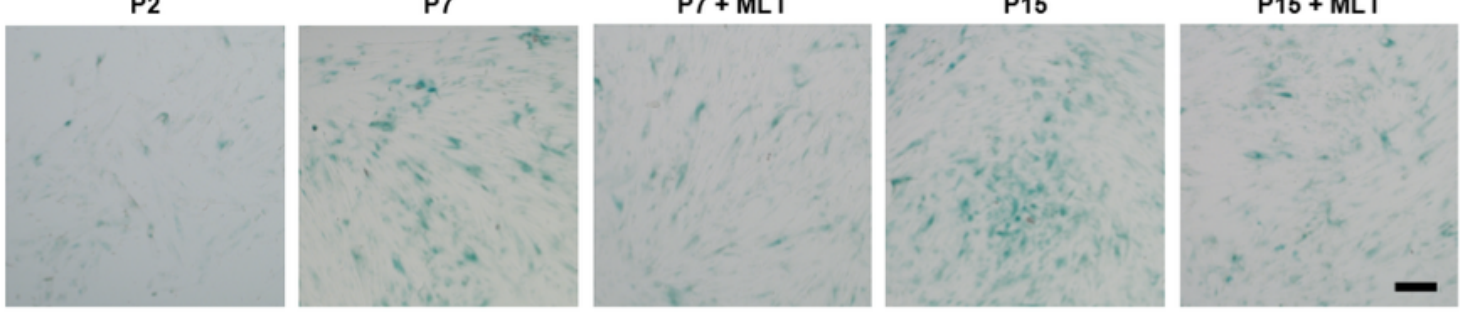

B

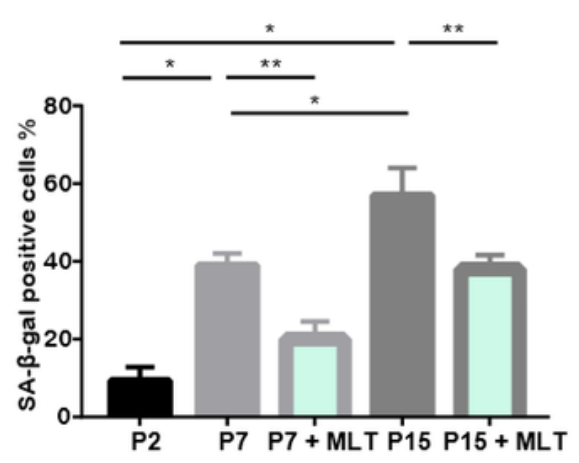

C

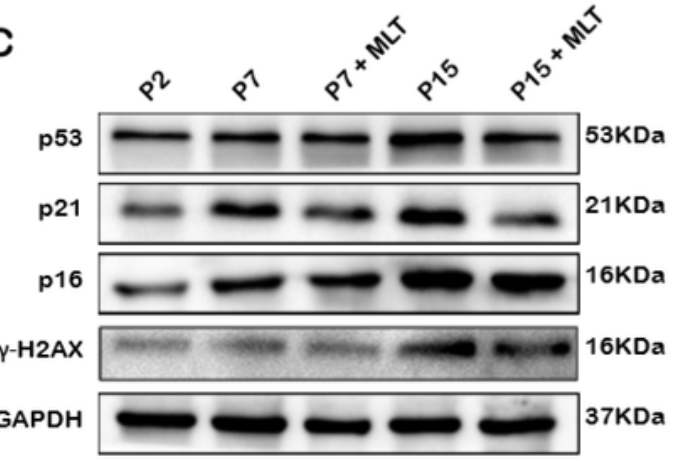

D
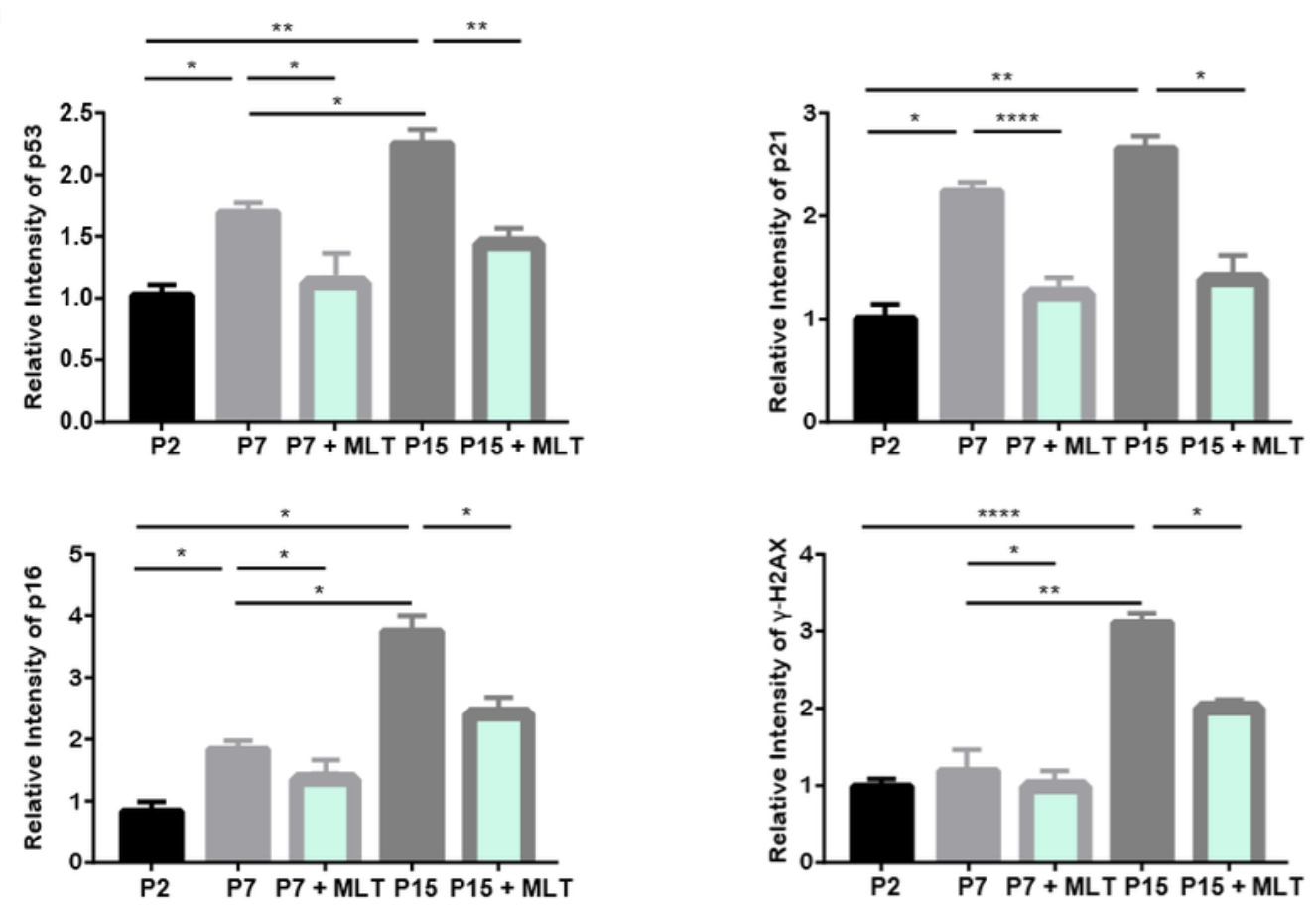

Figure 3

MLT rescues cells from long-term ex-vivo passaging-caused senescence (MLT-treated P2, P7 and P15

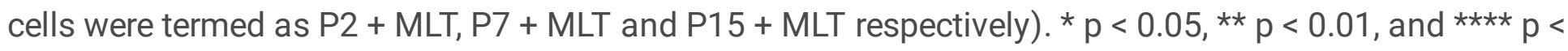
0.0001 represent significant differences between the indicated columns. (a) Representative images of SA$\beta$-gal expression in P2, P7 and P15 cells (immunocytochemical staining, positive stained cells were dyed in blue; scale bar = $100 \mu \mathrm{m}$ ); (b) Percentage of the SA- $\beta$-gal positive cells out of the total number of cells 
and quantitative analysis. (c) Cell senescence-related protein expressions in P2, P7 and P15 cells in terms of Western blot assay. (d) Quantitative analysis of p53, p21, p16 and $\mathrm{y}-\mathrm{H} 2 \mathrm{AX}$ expressions in P2, P7 and P15 cells.

A

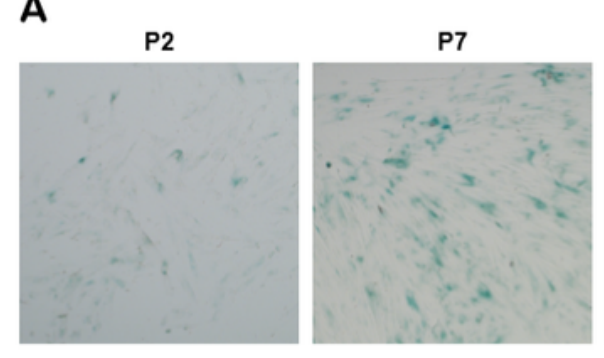

P7 + MLT

B
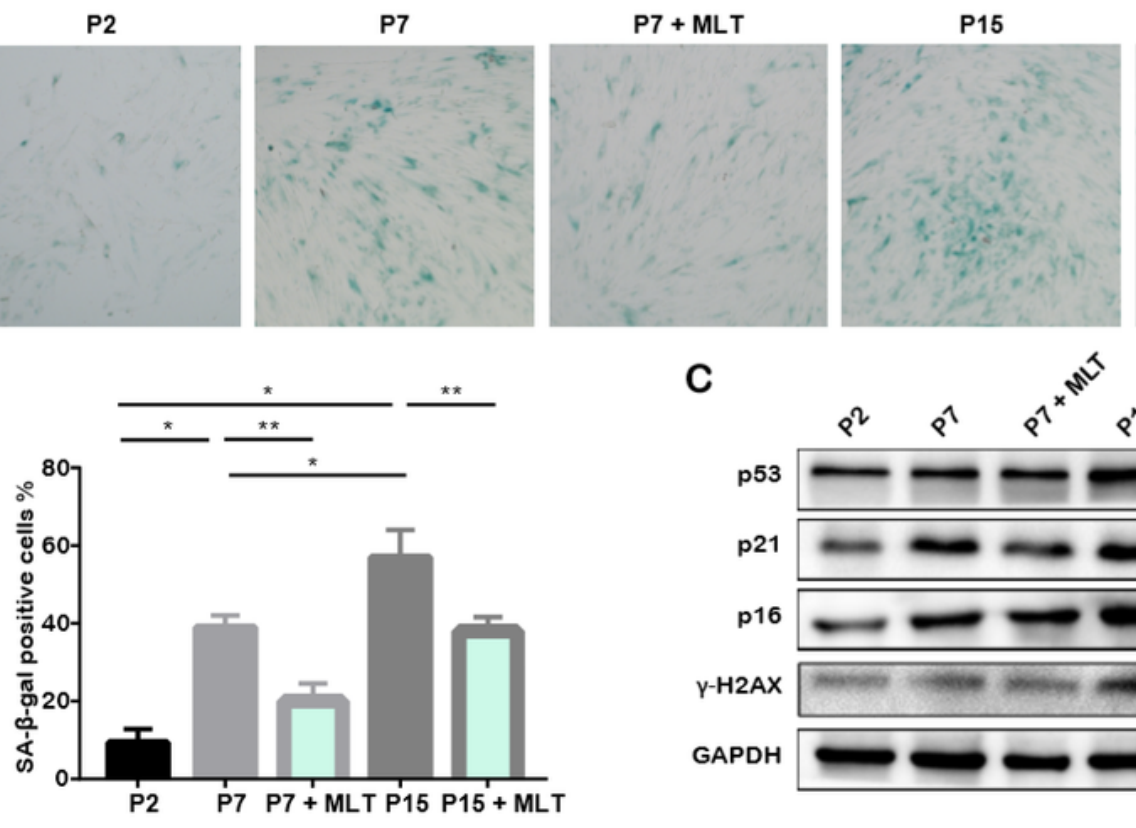

P15 + MLT

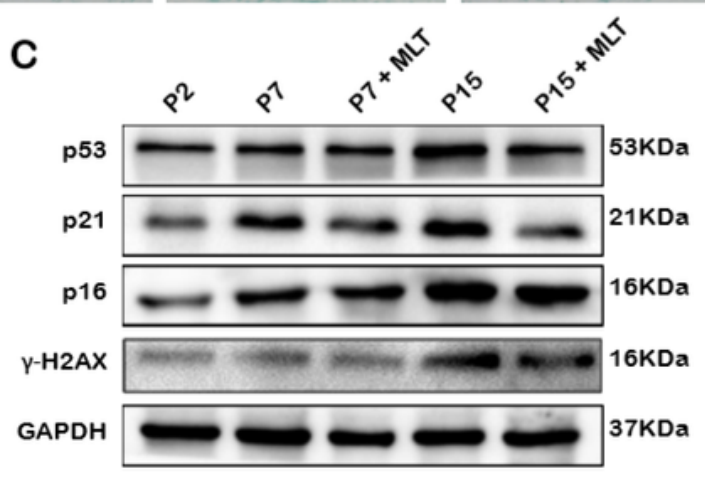

D
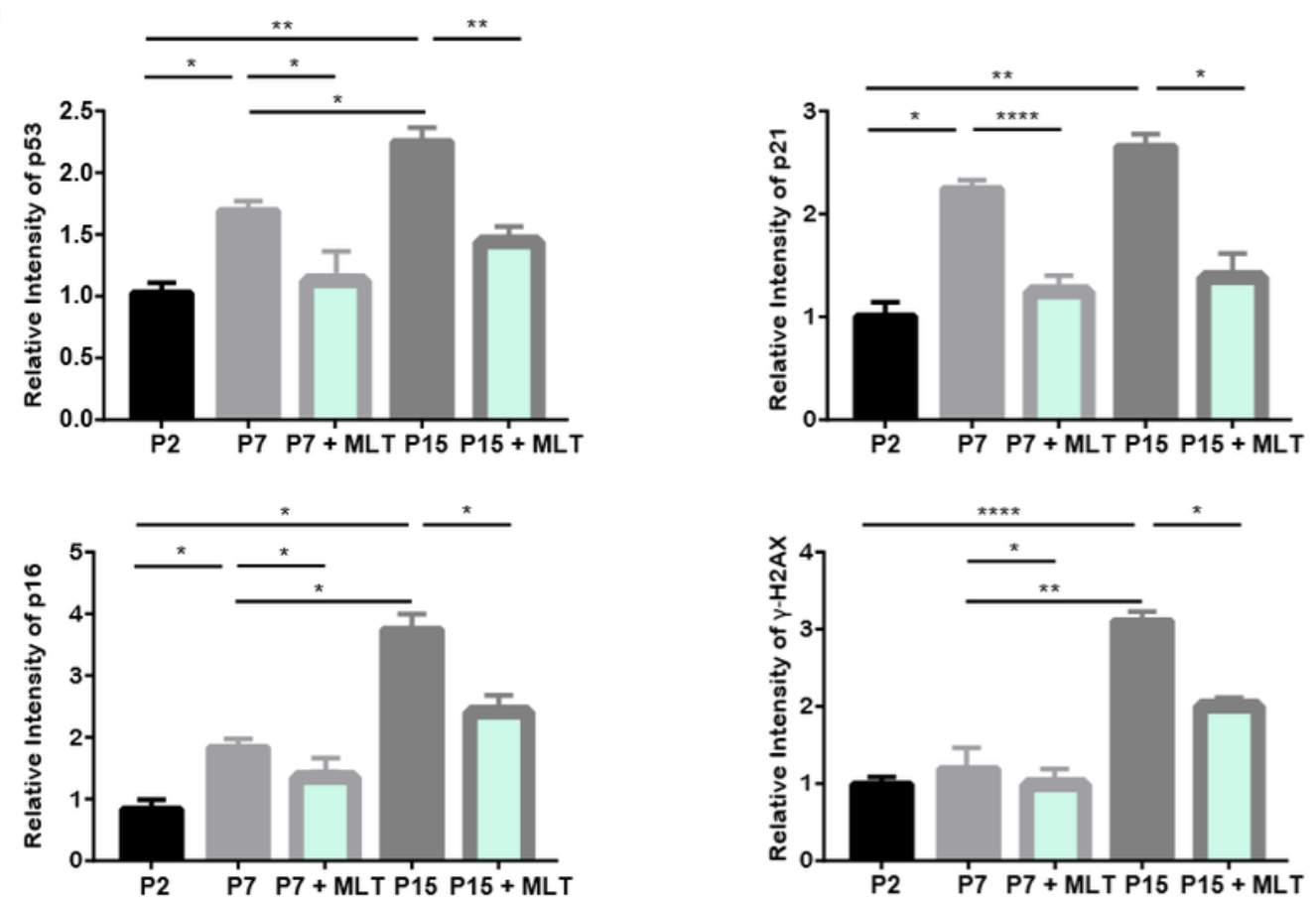

Figure 3

MLT rescues cells from long-term ex-vivo passaging-caused senescence (MLT-treated P2, P7 and P15 cells were termed as P2 + MLT, P7 + MLT and P15 + MLT respectively). * $p<0.05$, ** $p<0.01$, and **** $p<$ 
0.0001 represent significant differences between the indicated columns. (a) Representative images of SA$\beta$-gal expression in P2, P7 and P15 cells (immunocytochemical staining, positive stained cells were dyed in blue; scale bar $=100 \mu \mathrm{m}$ ); (b) Percentage of the SA- $\beta$-gal positive cells out of the total number of cells and quantitative analysis. (c) Cell senescence-related protein expressions in P2, P7 and P15 cells in terms of Western blot assay. (d) Quantitative analysis of p53, p21, p16 and y-H2AX expressions in P2, P7 and P15 cells.

A
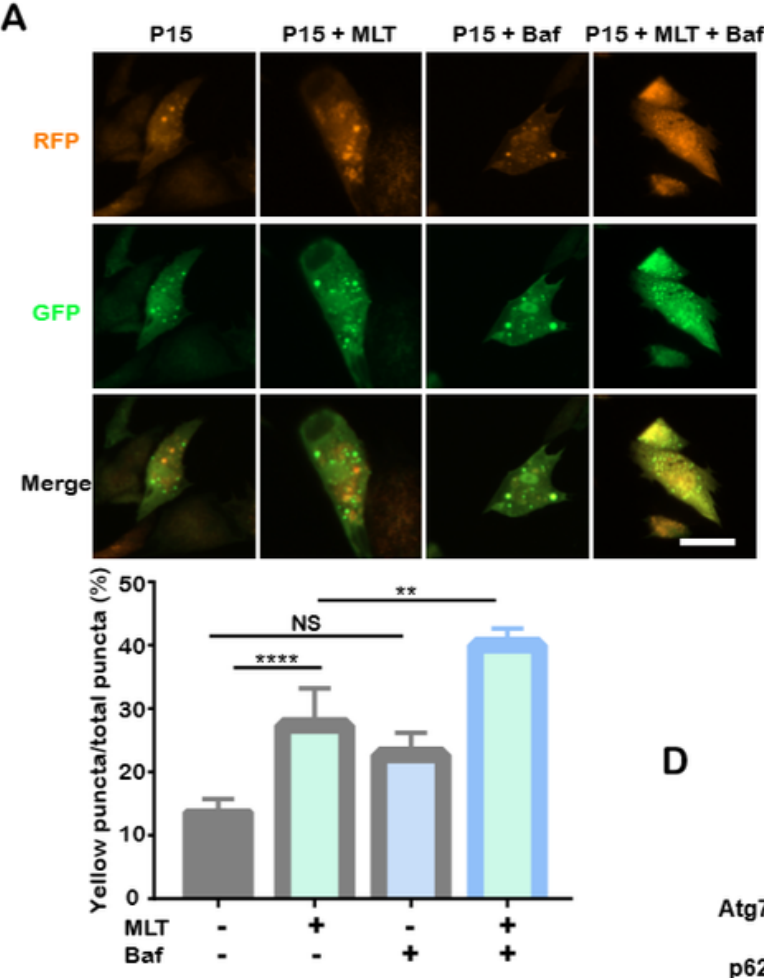

C
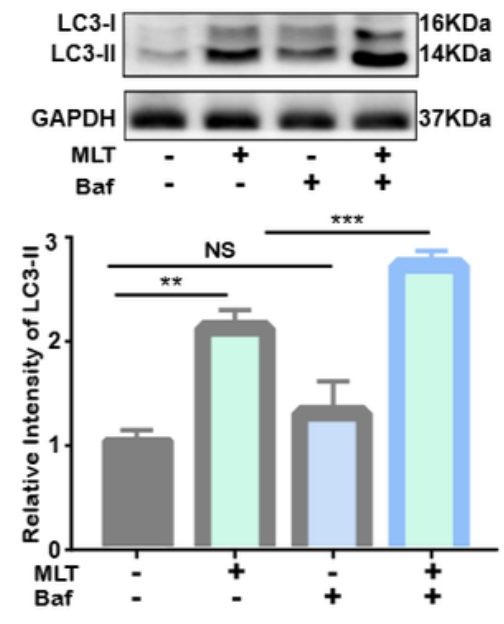

D
B
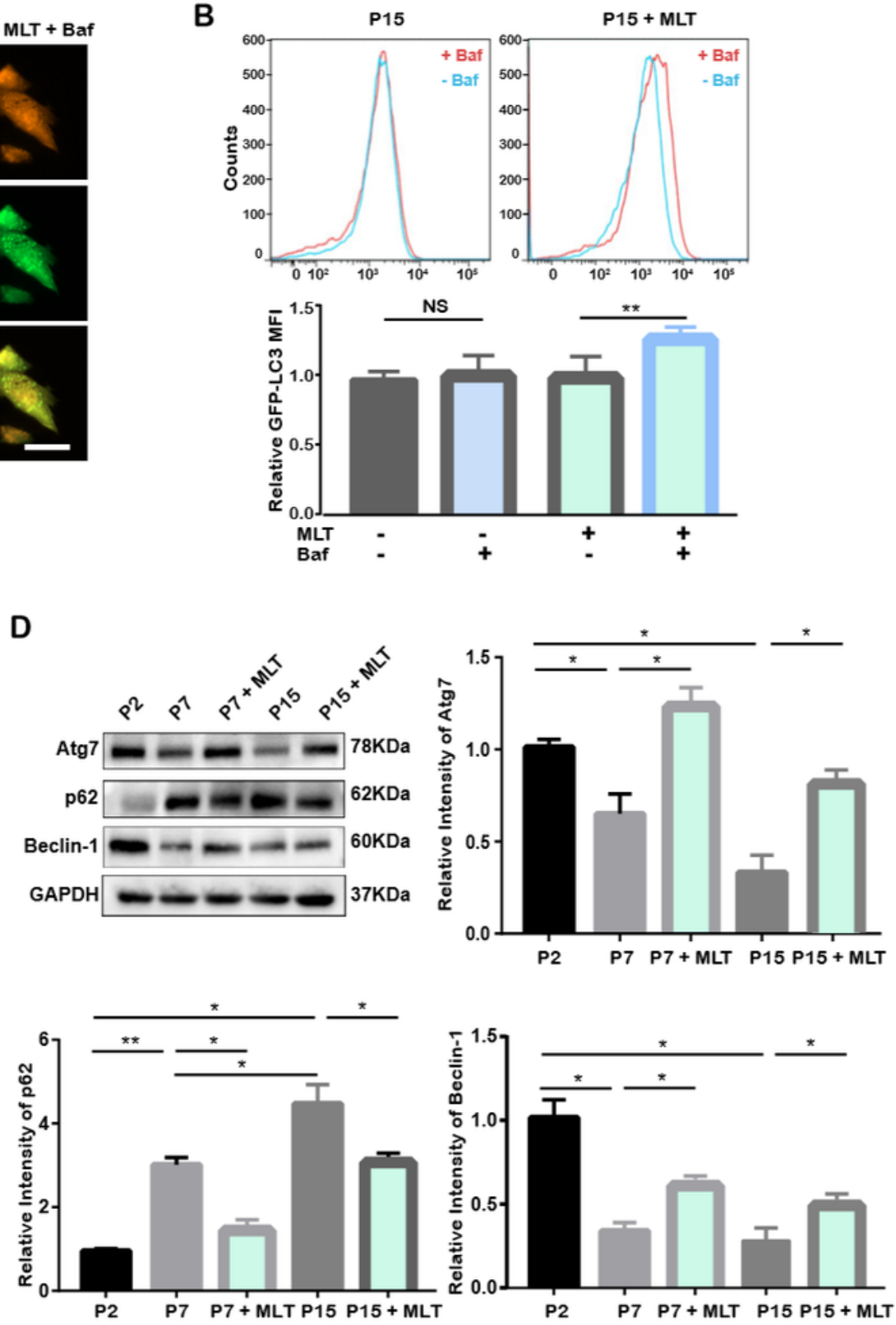

Figure 4 
MLT restores autophagy in cells undergone long-term ex-vivo passaging (MLT-treated P2, P7 and P15 cells were termed as P2 + MLT, P7 + MLT and P15 + MLT respectively). ${ }^{*} p<0.05,{ }^{*} p<0.01$, ${ }^{* \star} p<$ 0.001 and $* \star \star \star p<0.0001$ represent significant differences between the indicated columns, while NS represents no significant difference. (a) Presence of autophagosomes (yellow) and their maturation into autolysosomes (red) in adenovirus mRFP-GFP-LC3-transfected cells with or without MLT treatment (Top: Representative confocal images, scale bar $=50 \mu \mathrm{m}$, magnification, 200x; Bellow: Quantitative analysis for the percentage of the yellow puncta out of the total puncta based on confocal examination). (b) GFPLC3 fluorescence levels in P15 and MLT-treated P15 cells before and after Baf treatment (Top:

Representative flow cytometry graphs; Bellow: Quantitative analysis for MFI of GFP-LC3). (c) LC3-II levels in P2 and P15 cells before and after Baf treatment (Top: Protein levels of LC3-II in terms of Western blot assay; Bellow: Quantitative analysis of cell LC3-Il expressions). (d) Cell autophagy-related proteins in P2, P7, MLT-treated P7, P15 and MLT-treated P15 cells in terms of Western blot assay and quantitative analysis of Atg7, p62 and Beclin-1 expressions. 
A

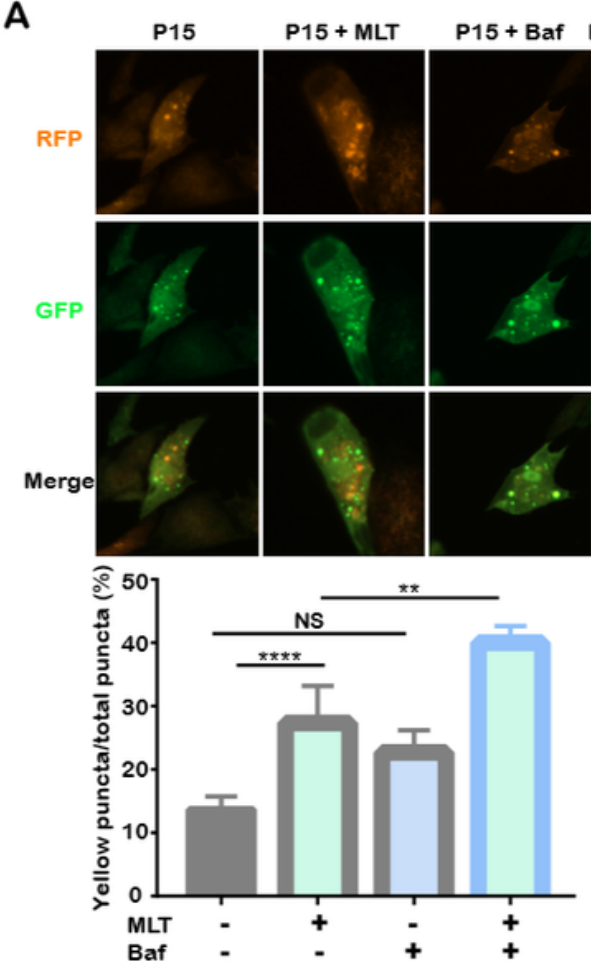

C
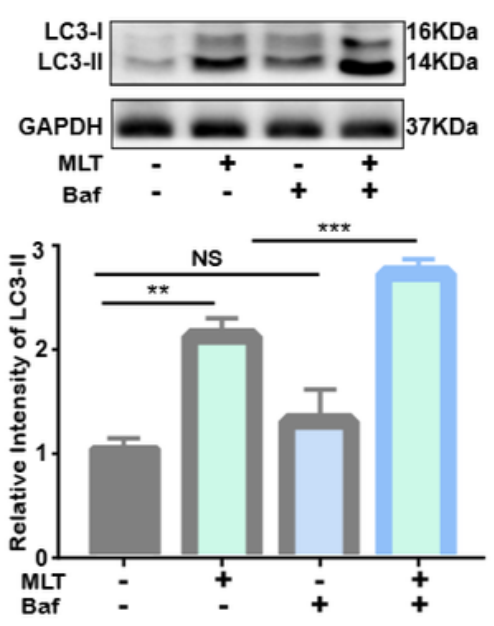

B
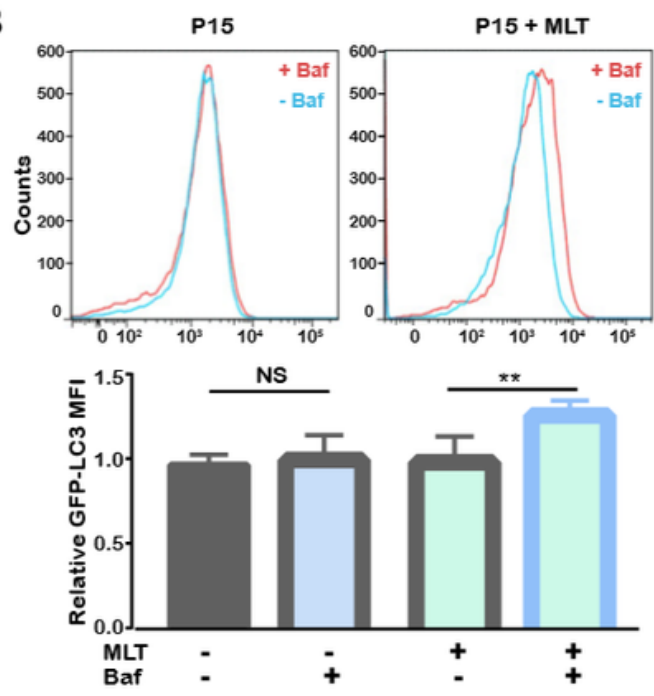

D

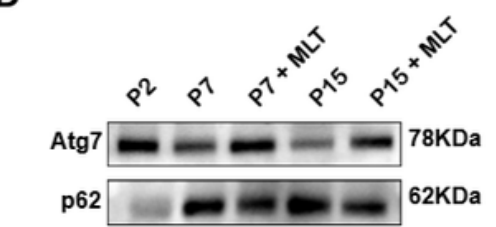

Beclin-1 - -

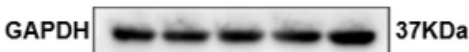
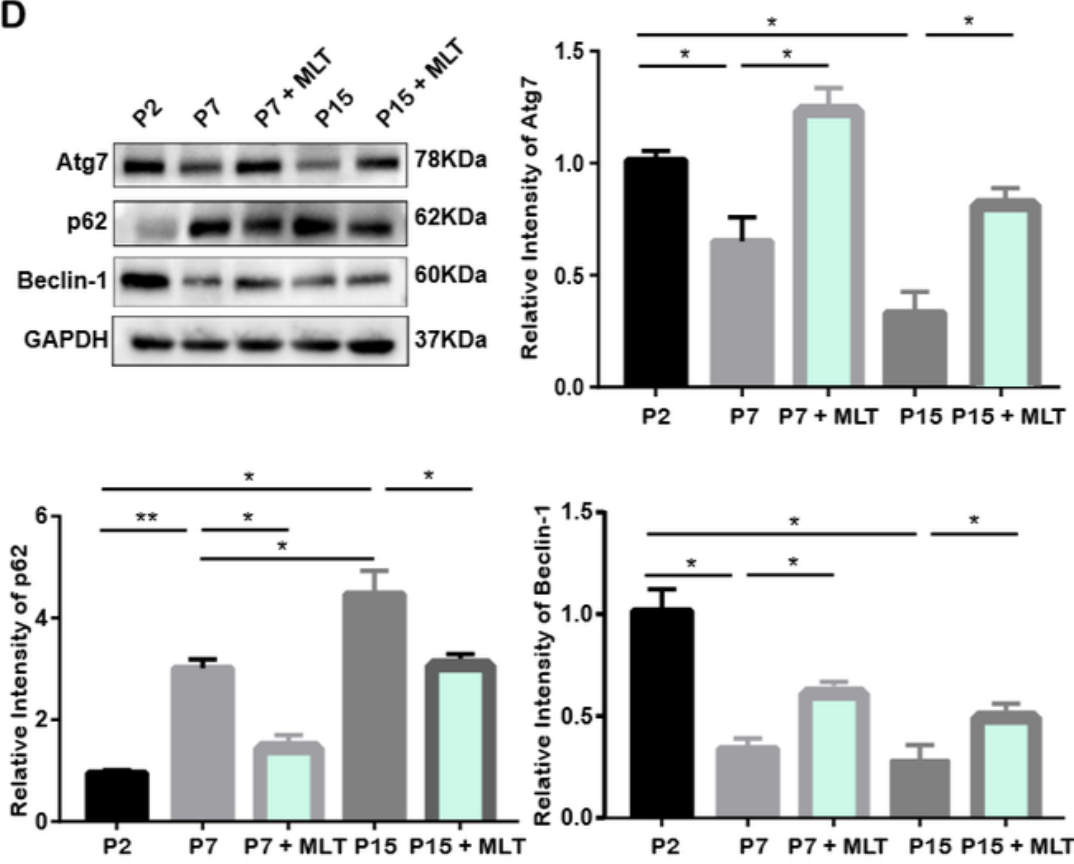

\section{Figure 4}

MLT restores autophagy in cells undergone long-term ex-vivo passaging (MLT-treated P2, P7 and P15 cells were termed as P2 + MLT, P7 + MLT and P15 + MLT respectively). * $p<0.05, * * p<0.01, * \star * p<$ 0.001 and $* \star \star \star ~ p<0.0001$ represent significant differences between the indicated columns, while NS represents no significant difference. (a) Presence of autophagosomes (yellow) and their maturation into autolysosomes (red) in adenovirus mRFP-GFP-LC3-transfected cells with or without MLT treatment (Top: 
Representative confocal images, scale bar $=50 \mu \mathrm{m}$, magnification, 200x; Bellow: Quantitative analysis for the percentage of the yellow puncta out of the total puncta based on confocal examination). (b) GFPLC3 fluorescence levels in P15 and MLT-treated P15 cells before and after Baf treatment (Top:

Representative flow cytometry graphs; Bellow: Quantitative analysis for MFI of GFP-LC3). (c) LC3-II levels in P2 and P15 cells before and after Baf treatment (Top: Protein levels of LC3-II in terms of Western blot assay; Bellow: Quantitative analysis of cell LC3-Il expressions). (d) Cell autophagy-related proteins in P2, P7, MLT-treated P7, P15 and MLT-treated P15 cells in terms of Western blot assay and quantitative analysis of Atg7, p62 and Beclin-1 expressions.
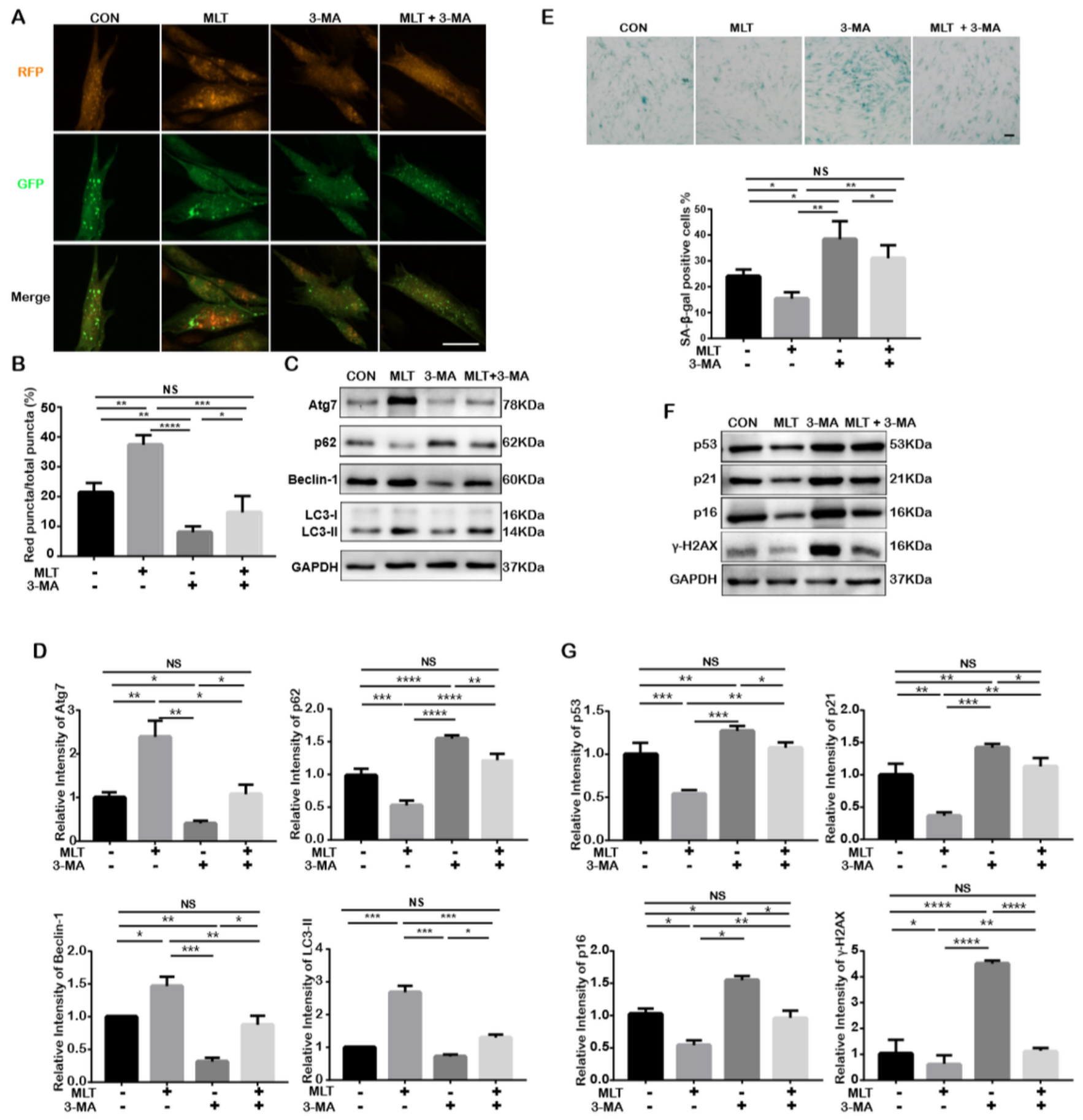


\section{Figure 5}

Down-regulation of autophagy via autophagy inhibitor deteriorates senescence in cells undergone longterm ex-vivo passaging (CON: P15 cells without any treatment; MLT: MLT-treated P15 cells; 3-MA: 3-MA-

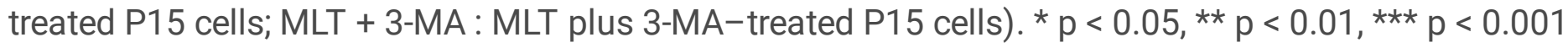
and $* \star \star * ~ p<0.0001$ represent significant differences between the indicated columns, while NS represents no significant difference. (a) Representative confocal images of autophagosomes (yellow) and their maturation into autolysosomes (red) in adenovirus mRFP-GFP-LC3-transfected P15 cells with or without MLT/3-MA treatment (scale bar = $50 \mu \mathrm{m}$, magnification, 200x). (b) Quantitative analysis for the percentage of the red puncta out of the total puncta based on confocal examination. (c) Cell autophagyrelated proteins of Atg7, p62, Beclin-1 and LC3-II in P15 cells with or without MLT/3-MA treatment in terms of Western blot assay. (d) Quantitative analysis of Atg7, p62, Beclin-1 and LC3-II expressions in P15 cells with or without MLT/3-MA treatment. (e) SA- $\beta$-gal in P15 cells with or without MLT/3-MA treatment (Top: Representative images of SA- $\beta$-gal expression in terms of immunocytochemical staining, positive stained cells were dyed in blue; scale bar $=100 \mu \mathrm{m}$; Bellow: Percentage of the SA- $\beta$-gal positive cells out of the total number of cells and quantitative analysis). (f) Cell senescence-related protein expressions in P15 cells with or without MLT/3-MA treatment in terms of Western blot assay. (g) Quantitative analysis of p53, p21, p16 and $y-H 2 A X$ expressions in P15 cells with or without MLT/3-MA treatment. 

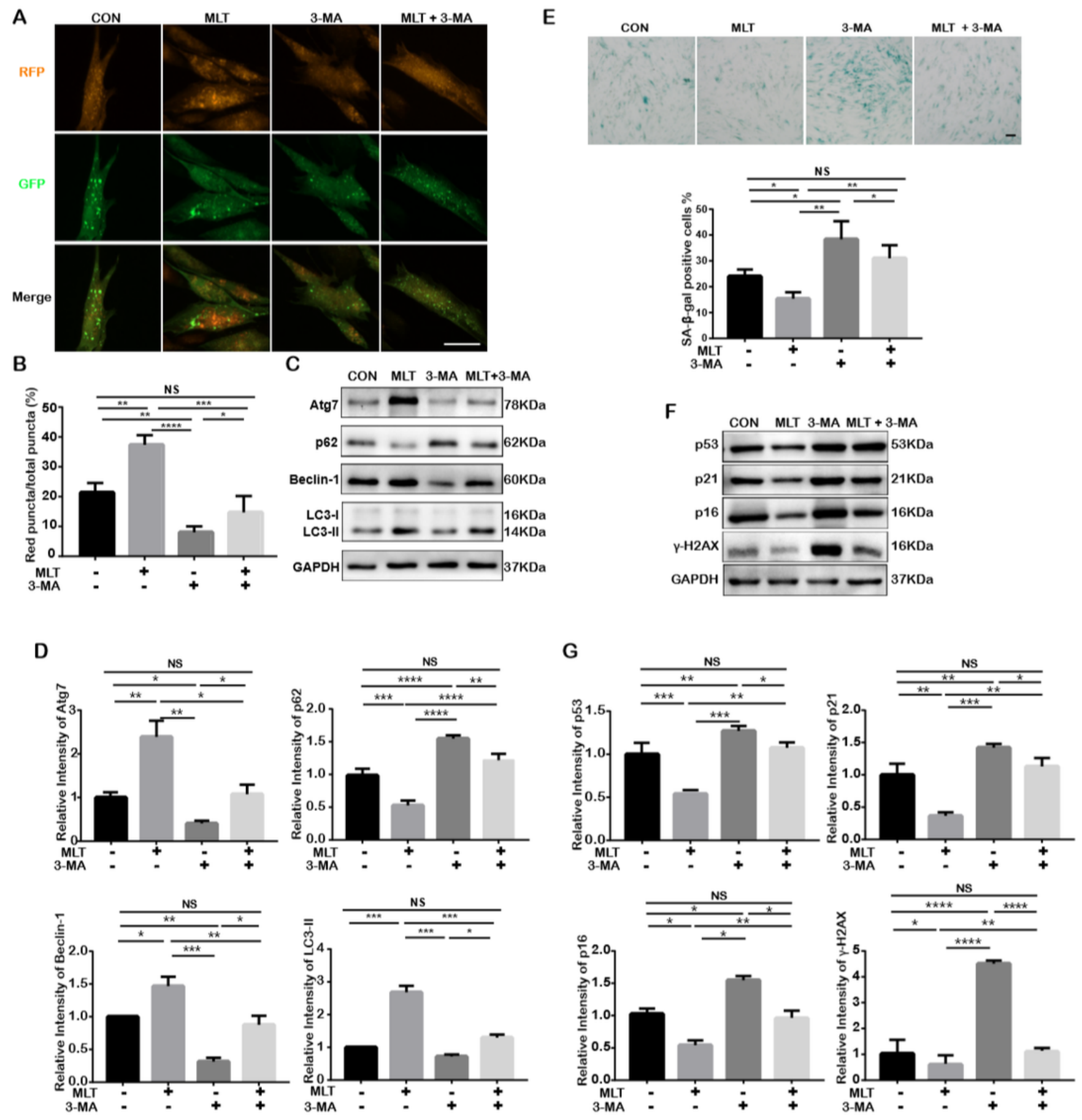

\section{Figure 5}

Down-regulation of autophagy via autophagy inhibitor deteriorates senescence in cells undergone longterm ex-vivo passaging (CON: P15 cells without any treatment; MLT: MLT-treated P15 cells; 3-MA: 3-MAtreated P15 cells; MLT + 3-MA : MLT plus 3-MA-treated P15 cells). * $p<0.05, * \star p<0.01, * \star * p<0.001$

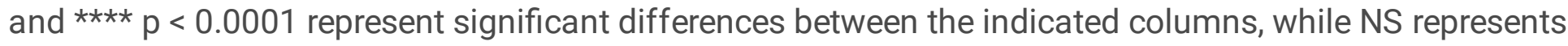
no significant difference. (a) Representative confocal images of autophagosomes (yellow) and their maturation into autolysosomes (red) in adenovirus mRFP-GFP-LC3-transfected P15 cells with or without 
MLT/3-MA treatment (scale bar $=50 \mu \mathrm{m}$, magnification, 200x). (b) Quantitative analysis for the percentage of the red puncta out of the total puncta based on confocal examination. (c) Cell autophagyrelated proteins of Atg7, p62, Beclin-1 and LC3-II in P15 cells with or without MLT/3-MA treatment in terms of Western blot assay. (d) Quantitative analysis of Atg7, p62, Beclin-1 and LC3-II expressions in P15 cells with or without MLT/3-MA treatment. (e) SA- $\beta$-gal in P15 cells with or without MLT/3-MA treatment (Top: Representative images of SA- $\beta$-gal expression in terms of immunocytochemical staining, positive stained cells were dyed in blue; scale bar $=100 \mu \mathrm{m}$; Bellow: Percentage of the SA- $\beta$-gal positive cells out of the total number of cells and quantitative analysis). (f) Cell senescence-related protein expressions in P15 cells with or without MLT/3-MA treatment in terms of Western blot assay. (g) Quantitative analysis of p53, p21, p16 and $\mathrm{y}-\mathrm{H} 2 \mathrm{AX}$ expressions in P15 cells with or without MLT/3-MA treatment. 
A
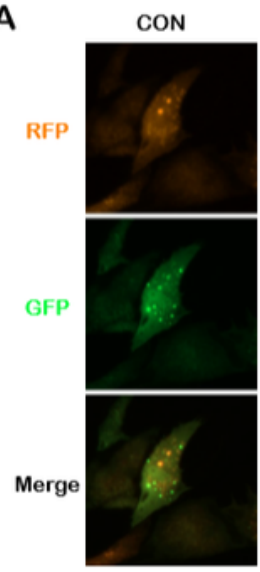

B

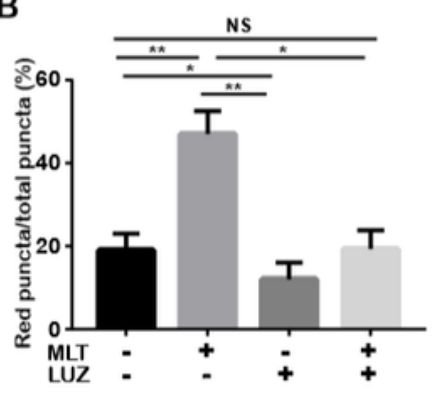

MLT
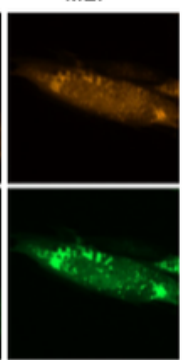

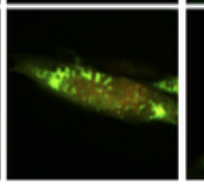

C

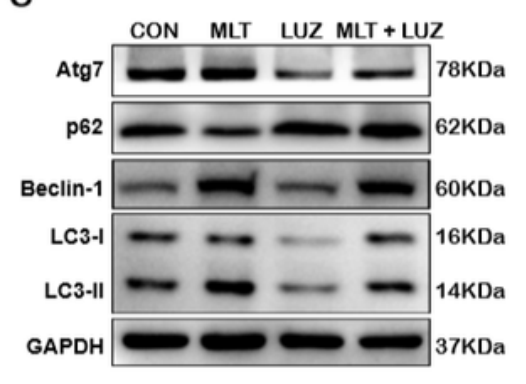

E

LUZ MLT + LUZ
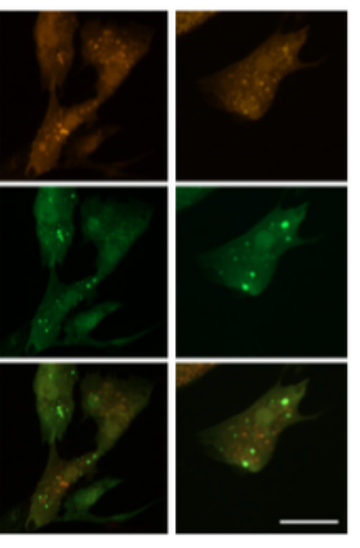
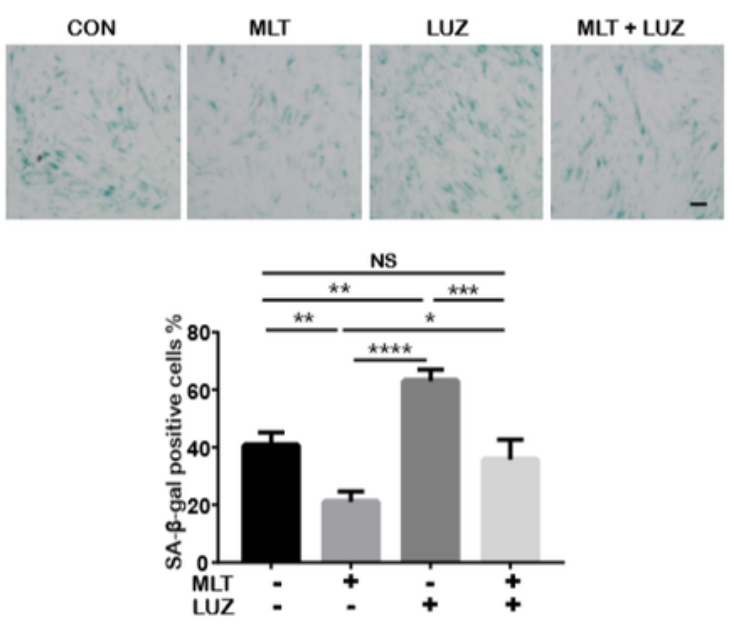

F

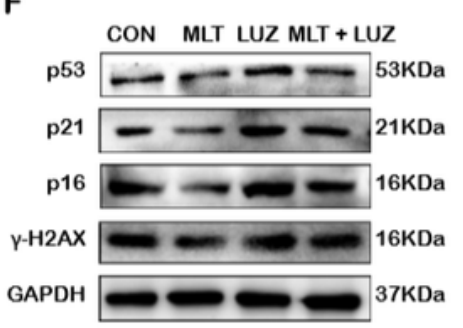

D
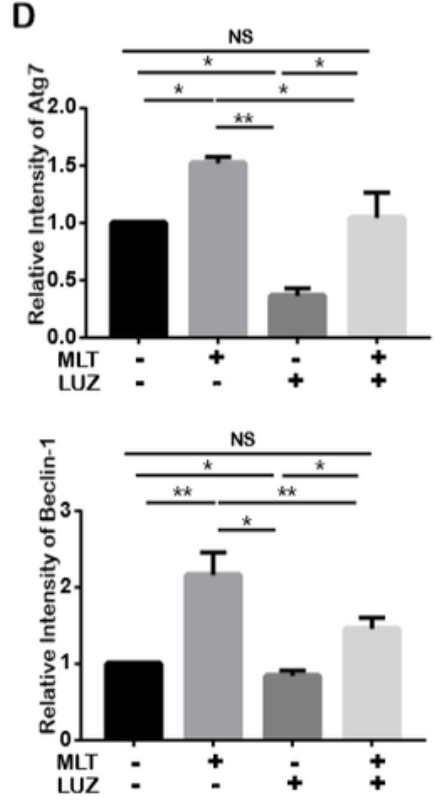

G
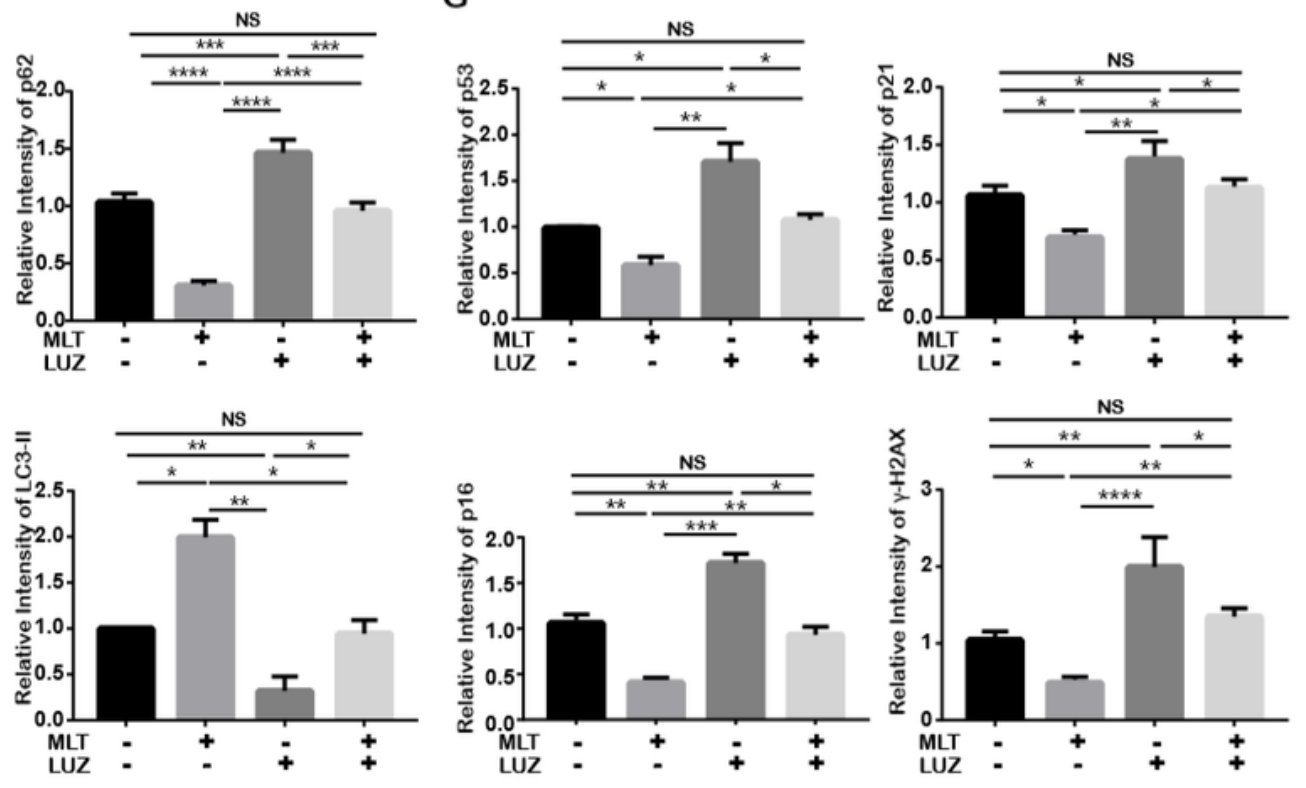

\section{Figure 6}

MT involves in MLT-mediated autophagy regulation in cells undergone long-term ex-vivo passaging (CON: P15 cells without any treatment; MLT: MLT-treated P15 cells; LUZ: LUZ-treated P15 cells; MLT + LUZ: MLT plus LUZ-treated P15 cells). * $p<0.05$, ** $p<0.01$, *** $p<0.001$ and ${ }^{\star * \star *} p<0.0001$ represent significant differences between the indicated columns, while NS represents no significant difference. (a) Representative confocal images of autophagosomes (yellow) and their maturation into autolysosomes 
(red) in adenovirus mRFP-GFP-LC3-transfected P15 cells with or without MLT/LUZ treatment (scale bar = $50 \mu \mathrm{m}$, magnification, 200x). (b) Quantitative analysis for the percentage of the red puncta out of the total puncta based on confocal examination. (c) Cell autophagy-related proteins of Atg7, p62, Beclin-1 and LC3-II in terms of Western blot assay. (d) Quantitative analysis of Atg7, p62, Beclin-1 and LC3-II expressions in P15 cells with or without MLT/LUZ treatment. (e) SA- $\beta$-gal in P15 cells with or without MLT/LUZ treatment. (Top: Representative images of SA- $\beta$-gal expression in terms of immunocytochemical staining, wherein positive stained cells were dyed in blue, scale bar $=100 \mu \mathrm{m}$; Bellow: Percentage of the SA- $\beta$-gal positive cells out of the total number of cells and quantitative analysis). (f) Cell senescence-related protein expressions in P15 cells with or without MLT/LUZ treatment in terms of Western blot assay. (g) Quantitative analysis of p53, p21, p16 and $\mathrm{y}-\mathrm{H} 2 \mathrm{AX}$ expressions in P15 cells with or without MLT/LUZ treatment. 
A
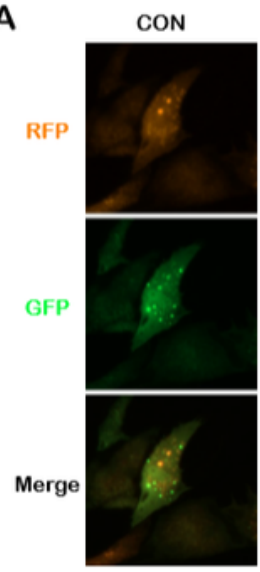

B

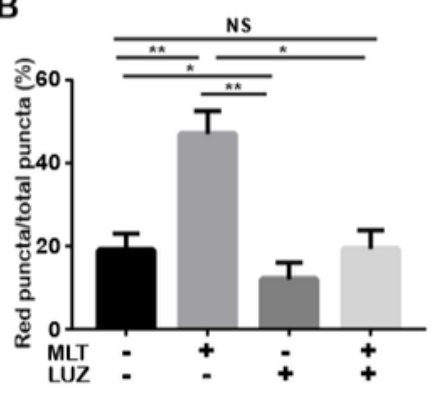

MLT
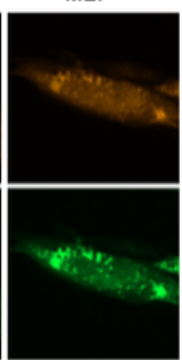

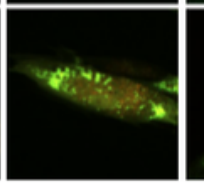

C

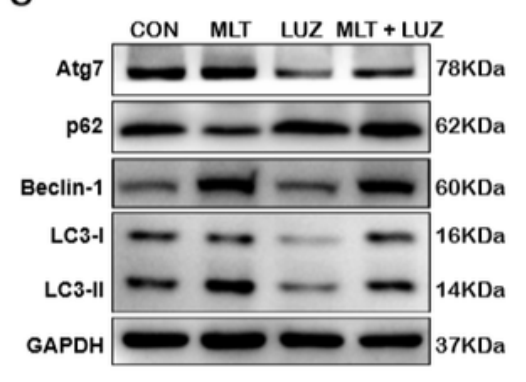

E

LUZ MLT + LUZ
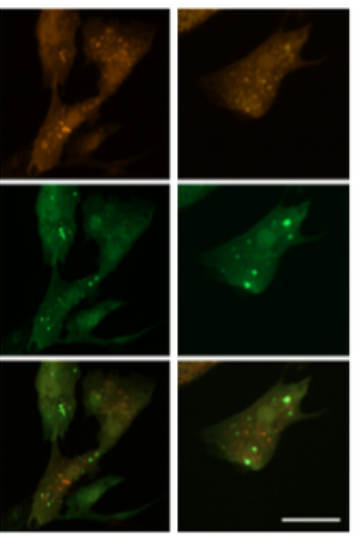

C
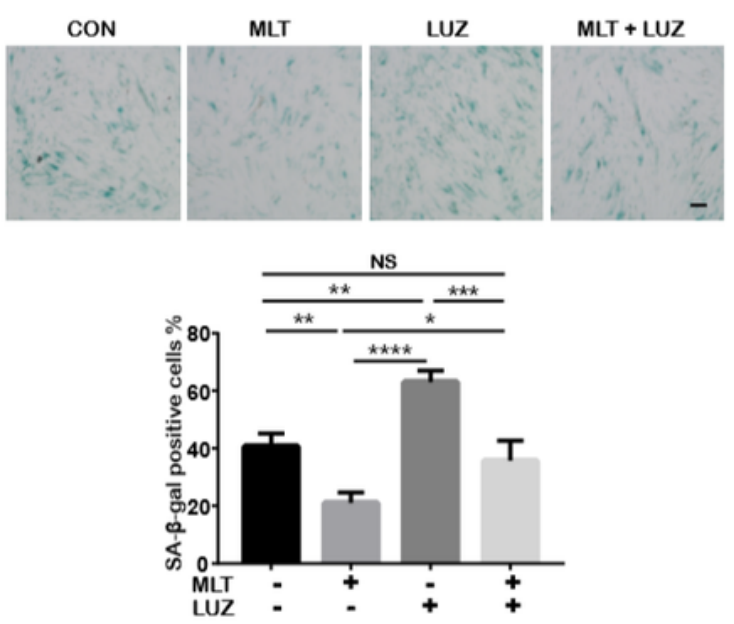

F

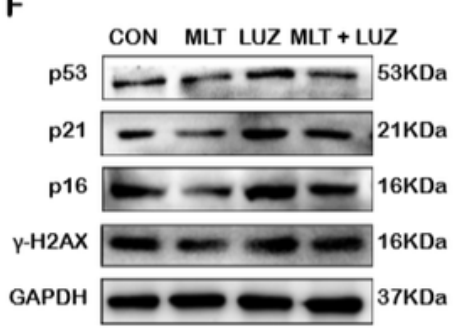

D
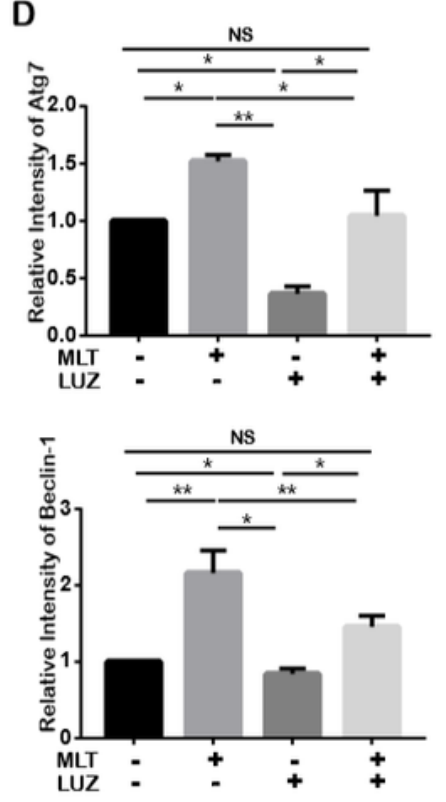

G
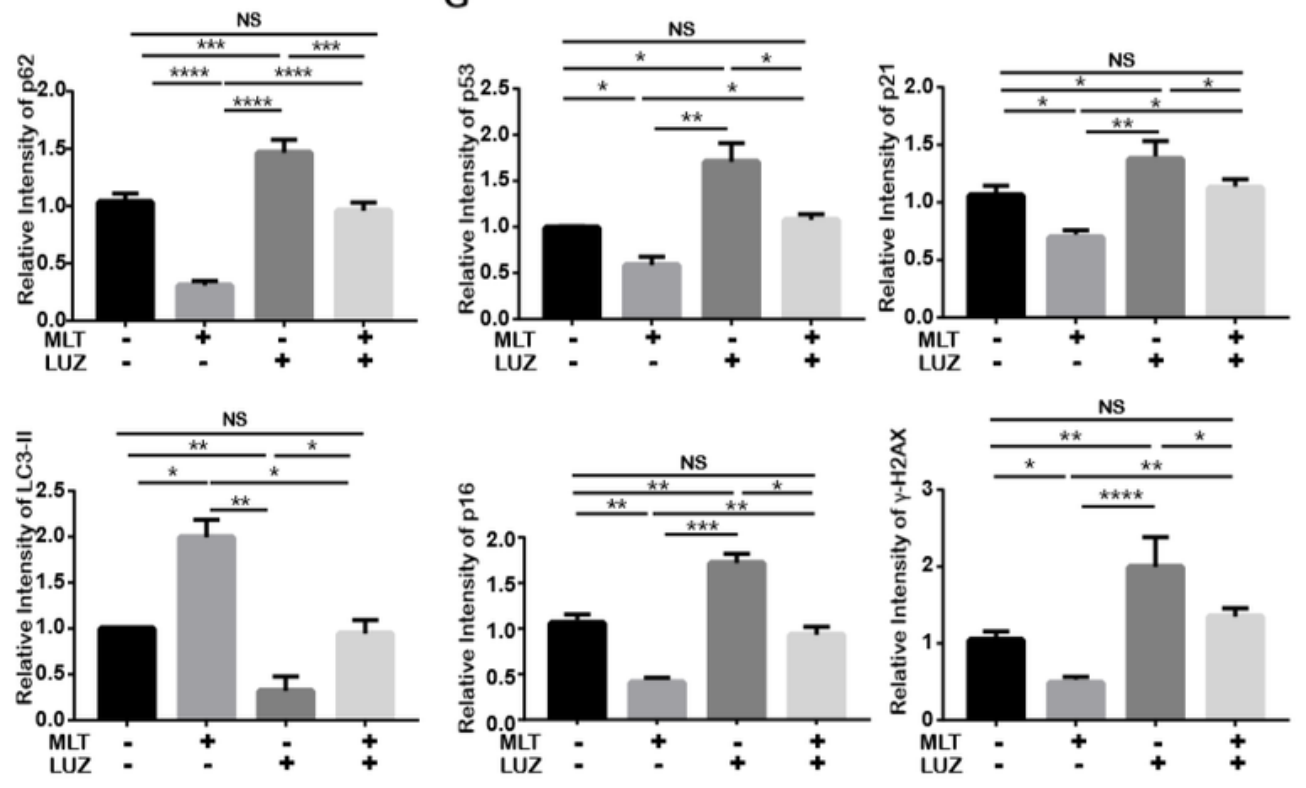

\section{Figure 6}

MT involves in MLT-mediated autophagy regulation in cells undergone long-term ex-vivo passaging (CON: P15 cells without any treatment; MLT: MLT-treated P15 cells; LUZ: LUZ-treated P15 cells; MLT + LUZ: MLT plus LUZ-treated P15 cells). * $p<0.05$, ** $p<0.01$, *** $p<0.001$ and ${ }^{\star * \star *} p<0.0001$ represent significant differences between the indicated columns, while NS represents no significant difference. (a) Representative confocal images of autophagosomes (yellow) and their maturation into autolysosomes 
(red) in adenovirus mRFP-GFP-LC3-transfected P15 cells with or without MLT/LUZ treatment (scale bar = $50 \mu \mathrm{m}$, magnification, 200x). (b) Quantitative analysis for the percentage of the red puncta out of the total puncta based on confocal examination. (c) Cell autophagy-related proteins of Atg7, p62, Beclin-1 and LC3-II in terms of Western blot assay. (d) Quantitative analysis of Atg7, p62, Beclin-1 and LC3-II expressions in P15 cells with or without MLT/LUZ treatment. (e) SA- $\beta$-gal in P15 cells with or without MLT/LUZ treatment. (Top: Representative images of SA- $\beta$-gal expression in terms of immunocytochemical staining, wherein positive stained cells were dyed in blue, scale bar $=100 \mu \mathrm{m}$; Bellow: Percentage of the SA- $\beta$-gal positive cells out of the total number of cells and quantitative analysis). (f) Cell senescence-related protein expressions in P15 cells with or without MLT/LUZ treatment in terms of Western blot assay. (g) Quantitative analysis of p53, p21, p16 and $\mathrm{y}-\mathrm{H} 2 \mathrm{AX}$ expressions in P15 cells with or without MLT/LUZ treatment.
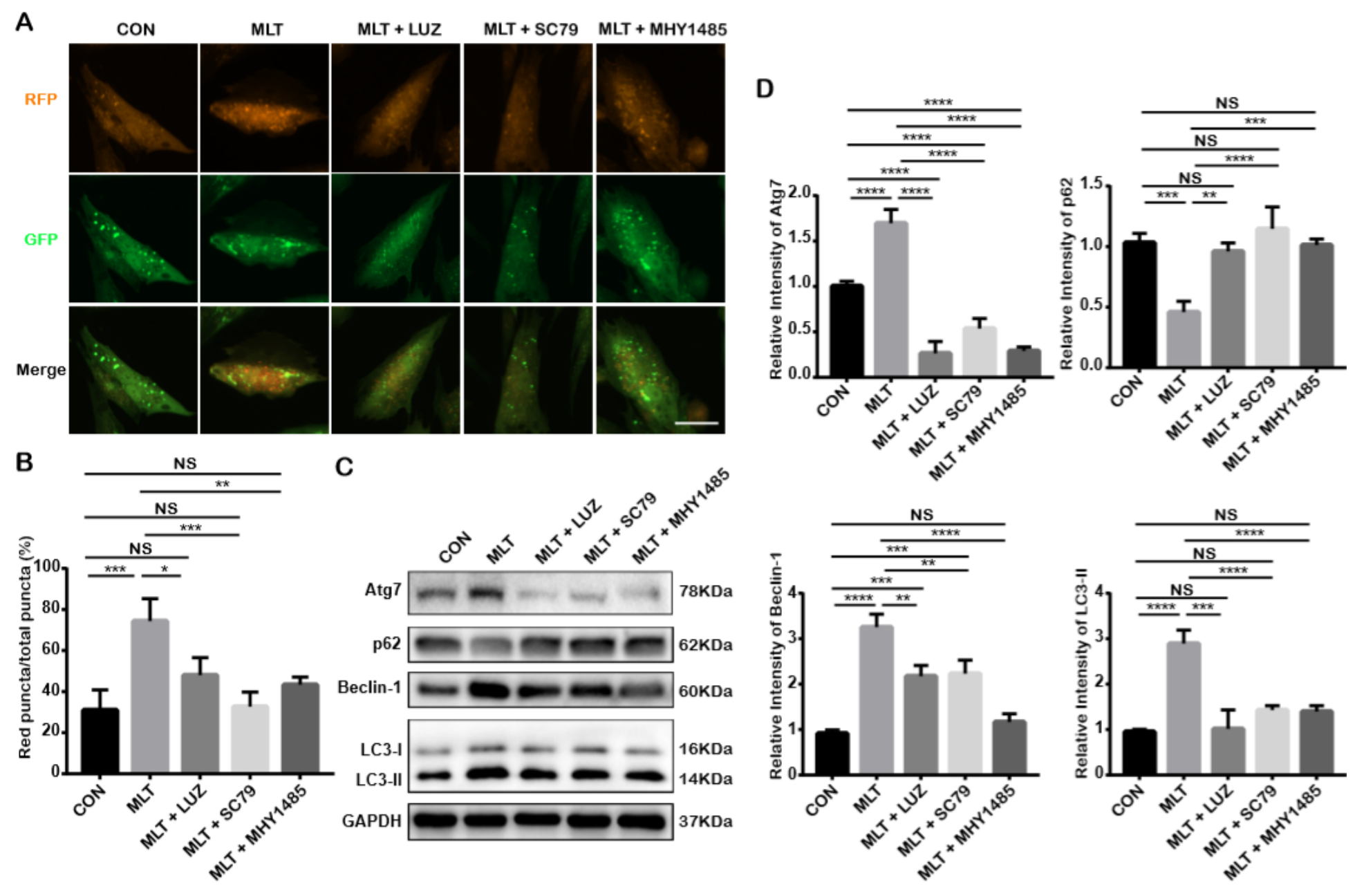

\section{Figure 7}
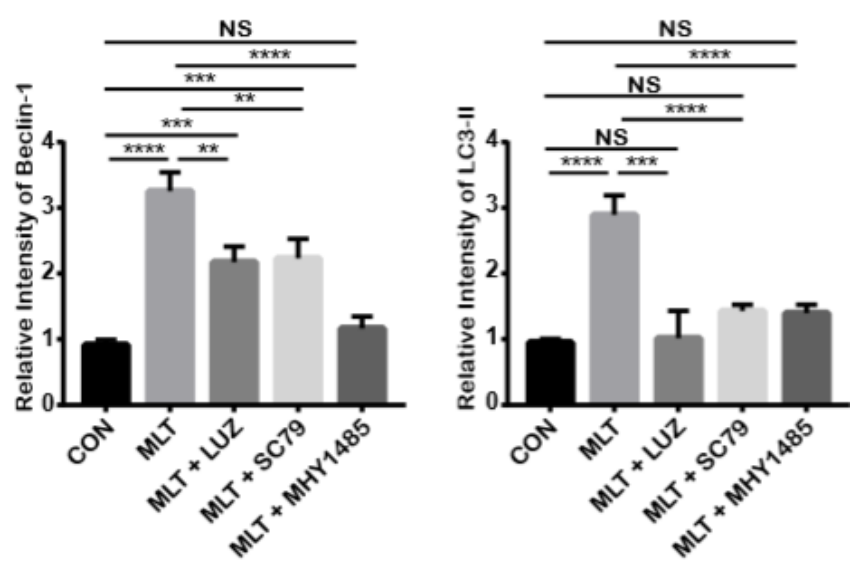

MT/PI3K/AKT/mTOR pathway involves in MLT-mediated autophagy regulation (CON: P15 cells without any treatment; MLT: MLT-treated P15 cells; MLT + LUZ: MLT plus LUZ-treated P15 cells; MLT + SC79: MLT plus SC79-treated P15 cells; MLT + MHY1485: MLT plus MHY1485-treated P15 cells). * $p<0.05, * \star p<$ 0.01 , $* \star \star p<0.001$ and $* \star \star \star p<0.0001$ represent significant differences between the indicated columns, while NS represents no significant difference. (a) Representative confocal images of autophagosomes (yellow) and their maturation into autolysosomes (red) in adenovirus mRFP-GFP-LC3-transfected P15 
cells with or without MLT/LUZ/SC79/MHY1485 treatment (scale bar = $50 \mu \mathrm{m}$, magnification, 200x). (b) Quantitative analysis for the percentage of the red puncta out of the total puncta based on confocal examination. (c) Cell autophagy-related proteins of Atg7, p62, Beclin-1 and LC3-II in P15 cells with or without MLT/LUZ/SC79/MHY1485 treatment in terms of Western blot assay. (d) Quantitative analysis of Atg7, p62, Beclin-1 and LC3-II expressions in P15 cells with or without MLT/LUZ/SC79/MHY1485 treatment.
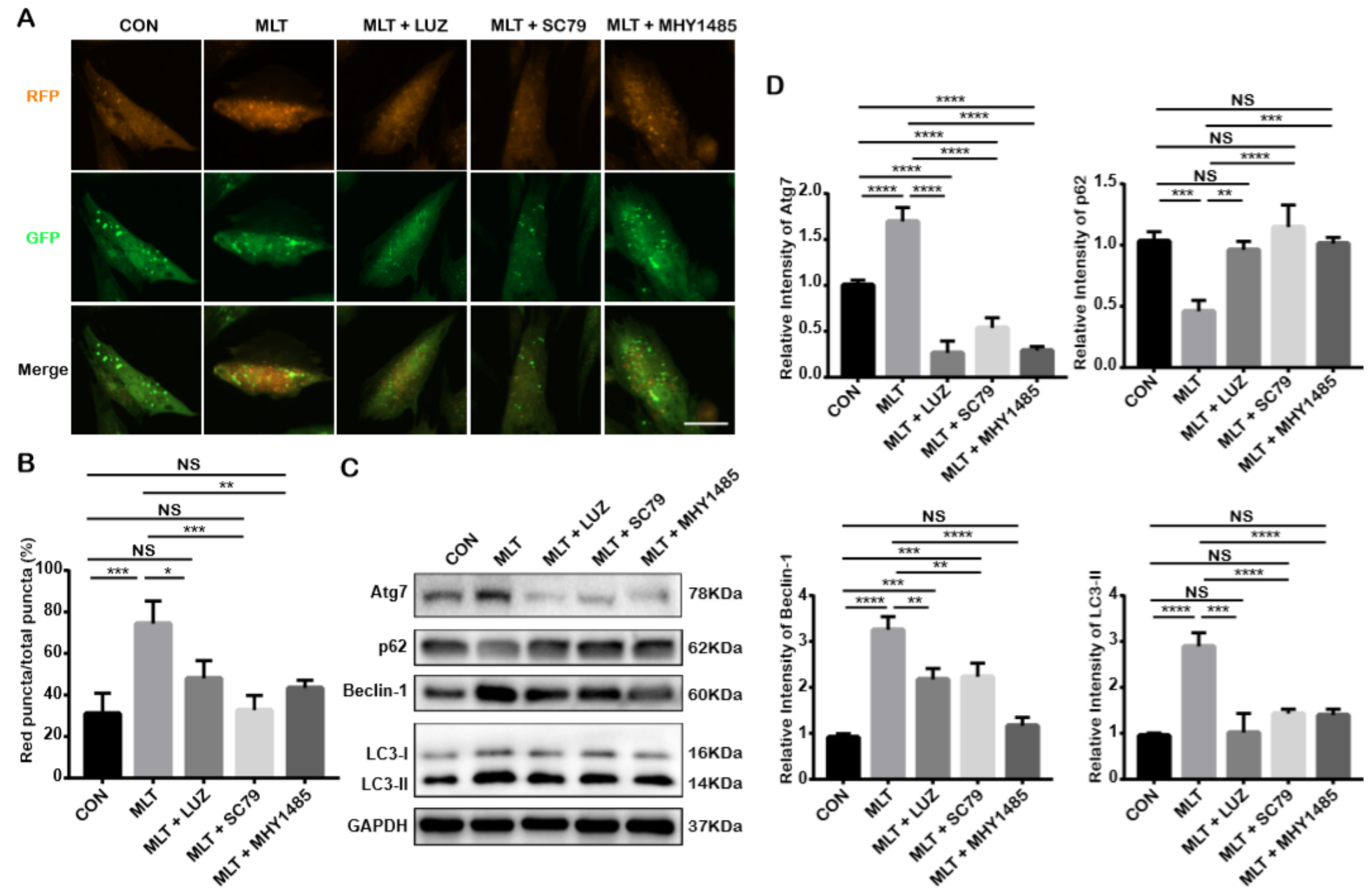

Figure 7

$\mathrm{MT} / \mathrm{PI}$ KK/AKT/mTOR pathway involves in MLT-mediated autophagy regulation (CON: P15 cells without any treatment; MLT: MLT-treated P15 cells; MLT + LUZ: MLT plus LUZ-treated P15 cells; MLT + SC79: MLT plus SC79-treated P15 cells; MLT + MHY1485: MLT plus MHY1485-treated P15 cells). * $p<0.05$, ** $p<$ $0.01, * \star * p<0.001$ and $* \star \star \star ~ p<0.0001$ represent significant differences between the indicated columns, while NS represents no significant difference. (a) Representative confocal images of autophagosomes (yellow) and their maturation into autolysosomes (red) in adenovirus mRFP-GFP-LC3-transfected P15 cells with or without MLT/LUZ/SC79/MHY1485 treatment (scale bar = $50 \mu \mathrm{m}$, magnification, 200x). (b) Quantitative analysis for the percentage of the red puncta out of the total puncta based on confocal examination. (c) Cell autophagy-related proteins of Atg7, p62, Beclin-1 and LC3-II in P15 cells with or without MLT/LUZ/SC79/MHY1485 treatment in terms of Western blot assay. (d) Quantitative analysis of 
Atg7, p62, Beclin-1 and LC3-II expressions in P15 cells with or without MLT/LUZ/SC79/MHY1485 treatment.
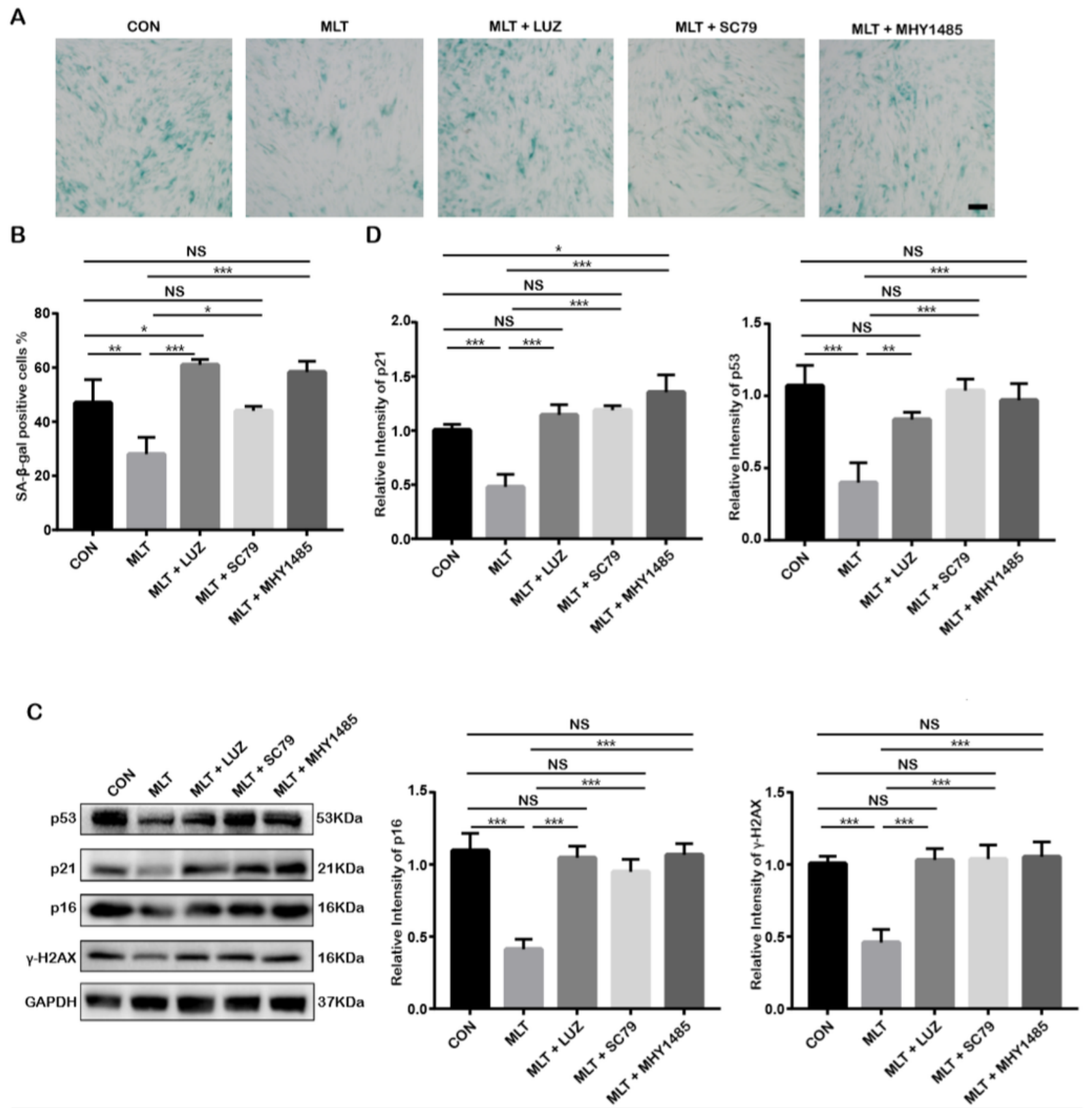

\section{Figure 8}

Down-regulation of autophagy via MT/PI3K/AKT/mTOR signaling deteriorates senescence in cells undergone long-term ex-vivo passaging (CON: P15 cells without any treatment; MLT: MLT-treated P15 cells; MLT + LUZ: MLT plus LUZ-treated P15 cells; MLT + SC79: MLT plus SC79-treated P15 cells; MLT + MHY1485: MLT plus MHY1485-treated P15 cells). * $p<0.05, * \star p<0.01, * \star \star p<0.001$ and ${ }^{* \star \star \star} p<0.0001$ represent significant differences between the indicated columns, while NS represents no significant 
difference. (a) Representative images of SA- $\beta$-gal expression in P15 cells with or without MLT/LUZ/SC79/MHY1485 treatment (immunocytochemical staining, positive stained cells were dyed in blue; scale bar $=100 \mu \mathrm{m})$; (b) Percentage of the SA- $\beta$-gal positive cells out of the total number of cells and quantitative analysis. (c) Cell senescence-related protein expressions in P15 cells with or without MLT/LUZ/SC79/MHY1485 treatment in terms of Western blot assay. (d) Quantitative analysis of p53, p21, p16 and $\mathrm{y}-\mathrm{H} 2 \mathrm{AX}$ expressions in P15 cells with or without MLT/LUZ/SC79/MHY1485 treatment.
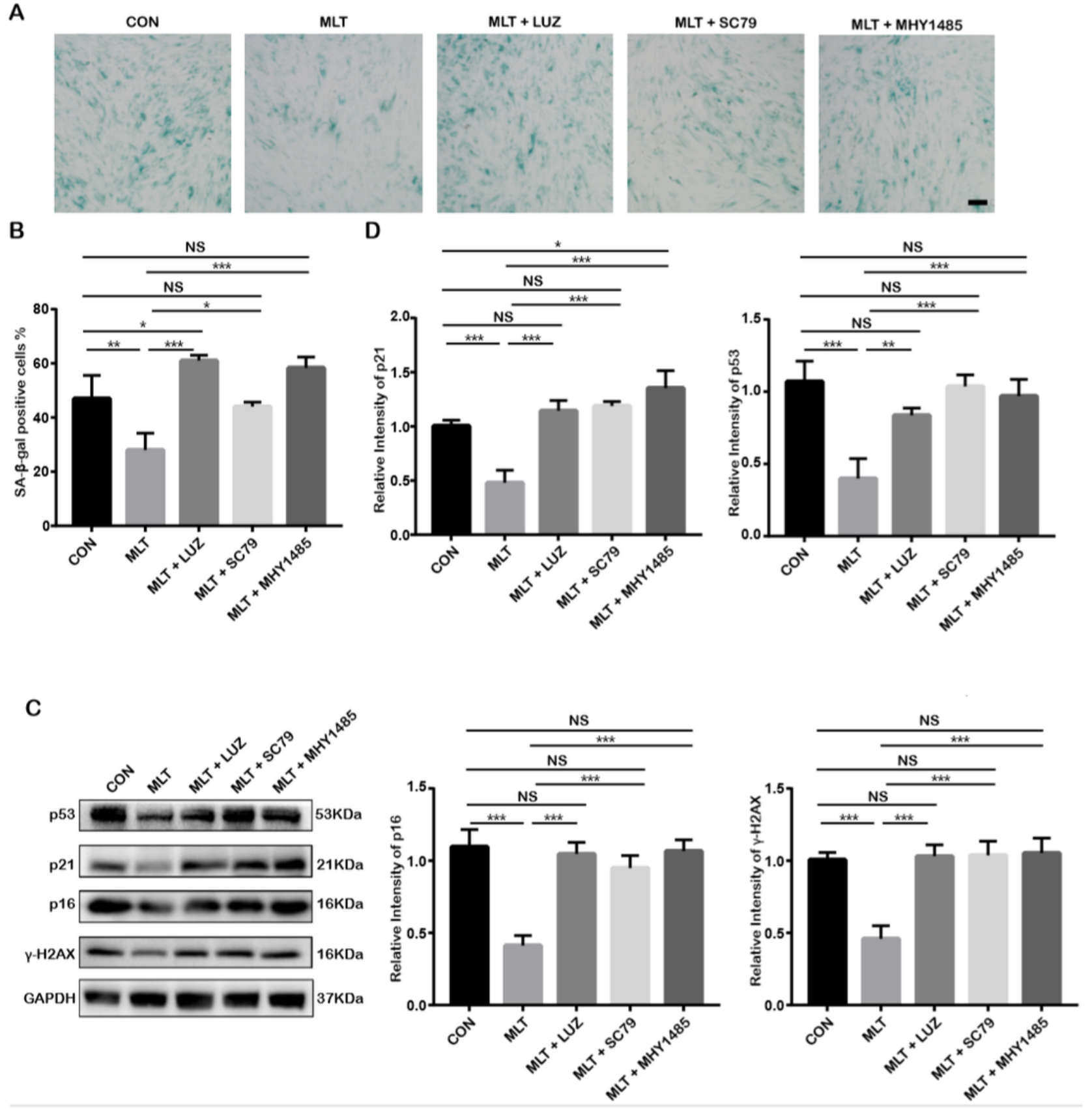

Figure 8 
Down-regulation of autophagy via MT/PI3K/AKT/mTOR signaling deteriorates senescence in cells undergone long-term ex-vivo passaging (CON: P15 cells without any treatment; MLT: MLT-treated P15 cells; MLT + LUZ: MLT plus LUZ-treated P15 cells; MLT + SC79: MLT plus SC79-treated P15 cells; MLT + MHY1485: MLT plus MHY1485-treated P15 cells). ${ }^{*} p<0.05$, ${ }^{* *} p<0.01, * * * p<0.001$ and ${ }^{* * * *} p<0.0001$ represent significant differences between the indicated columns, while NS represents no significant difference. (a) Representative images of SA- $\beta$-gal expression in P15 cells with or without MLT/LUZ/SC79/MHY1485 treatment (immunocytochemical staining, positive stained cells were dyed in blue; scale bar $=100 \mu \mathrm{m})$; (b) Percentage of the SA- $\beta$-gal positive cells out of the total number of cells and quantitative analysis. (c) Cell senescence-related protein expressions in P15 cells with or without MLT/LUZ/SC79/MHY1485 treatment in terms of Western blot assay. (d) Quantitative analysis of p53, p21, p16 and $\mathrm{Y}-\mathrm{H} 2 \mathrm{AX}$ expressions in P15 cells with or without MLT/LUZ/SC79/MHY1485 treatment.

\section{Supplementary Files}

This is a list of supplementary files associated with this preprint. Click to download.

- FigS1.pdf

- FigS1.pdf

- FigS2.pdf

- Figs2.pdf

- FigS3.pdf

- FigS3.pdf 